\title{
Correlation of Types of Cortical Grain Structure with Architectural Features of the Human Skull '
}

\author{
WILFRID T. DEMPSTER \\ Department of Anatomy, University of Michigan, \\ Ann Arbor, Michigan
}

\begin{abstract}
Seven grain-form relationships, as indicated by the split-line patterns, are recognized in the cortical bone of the adult human skull: (1) random pattern of braincase, (2) planes and (3) ridges with elongated grain, (4) troughs with transverse grain, (5) concavities with circular grain, (6) edges, and (7) spines. Concavities may show superimposed trough or ridge structure, and troughs may be marked by localized ridges and planes. That is, trough patterns are dominant over concavity patterns, and ridge patterns are dominant over both trough and concavity patterns. Finally, there are a few small cranial areas that are random distributions in some skulls and planes in others; the skull vault proper, however, except for the forehead region and internal sagittal markings, has a random pattern throughout.

The mechanical significance of the various patterns and the areas on which they are found are discussed and explained on the basis of principles of mechanics and architecture. The form-texture relationships are discussed as architectural features of the skull, and their adequacy and limitations are analyzed in terms of their reaction to force systems and their proneness to fracture.
\end{abstract}

Does the grain structure of cortical bone make the human skull stronger or weaker? An attempt to answer this question brings to light several unrecognized relationships. Distinctive patterns of grain texture are found on the eminences, fossae, processes, and certain other markings of the adult skull, and similar forms all over the skull have similar grain patterns. These form-texture relationships at first sight suggest that some mechanical advantage might accrue from the relationship. This paper, then, (1) examines the several form-texture relationships to clarify the various grain patterns that are repeatedly found, (2) lists nearly 150 skull forms with their characteristic textures to attest to the generality of the finding, and (3) examines the mechanical and architectural features of these form-texture relationships with regard to the weak and strong features of skull architecture and to fracture mechanics. Finally, the current interpretations of force "trajectories" of the skull are criticized.

Forty years ago, Benninghoff ('25) demonstrated an architectural pattern or "grain" in the fibromatrix of the cortex of several flat bones, including those of the skull. Bones were decalcified in acid and punctured with a needle dipped in India ink; instead of round holes, the punctures usually produced elongate, ink-marked "split-lines" that indicated a grain direction in the organic matrix. They were similar in appearance to Langer's (1861) split-lines of the skin, Hultzkranz's (1898) split-lines in joint cartilage, Benninghoff's ('34) split pattern in mucous membrane, Bühler's ('34) puncture patterns in laryngeal cartilages, and Ilberg's ('35) puncture patterns in nasal cartilages.

Although Tappen ('53) published photographs showing split-line patterns in an adult human skull, Benninghoff's original study, including illustrations of the facial, lateral, and interior basal regions, is the most complete demonstration to date of the grain of the adult skull. Dowgjallo ('32) and Seipel ('48) reported more highly detailed split-line studies of the mandible. (A study of vascular canals in the cortex of the mandible - Dempster and Enlow, '59 - by an ink injectionclearing technique, revealed still more elaborate patterns of 11 tracts.) Bruhnke ('29) used the split-line technique on the horse skull, Henckel ('31) on several mammalian skulls, Tappen ('53, '54, '64) on primate skulls, and Ahrens ('36) on

1 This investigation was entirely supported by $\mathrm{Na}$ tional Science Foundation grant GB-356. 
various child skulls. None of these studies, however, covers the entire skill or correlates grain with structural features.

The present study reports a more extensive investigation than others have made into the grain patterns of the bones of the whole skull, excluding the mandible. The split-line technique was used on six complete adult skulls (new commercial osteological material) and on miscellaneous parts of some damaged discards. The skulls were soaked overnight in $10 \%$ formalin to fix the protein constituents; then the skulls were decalcified for short periods in $5 \%$ or $10 \% \mathrm{HCl}$. The material in acid was tested with a needle at intervals until the thinnest regions could be easily punctured. If left too long, excessive decalcification resulted in blurring and smudging of the split-lines. A sewing needle, mounted in a jeweler's pin vise and dipped in India ink, was used to puncture the decalcified bone; after each puncture, excess ink was wiped away with a bit of wet cotton wool to avoid indiscriminate staining. After the thin areas had been treated, the skulls were returned to the acid for further decalcification of the thicker areas; these areas were then punctured as above, with little deterioration of the split-lines in thin areas.

Best results were obtained when the specimens were decalcified in a buffer mixture of formic acid ( $8 \mathrm{~N})$ and sodium formate $(1 N)$. Most of the material was stored in $80 \%$ alcohol and could be photographed after draining. Other material was allowed to dry slowly and thoroughly to produce hard, and somewhat shrunken, dry specimens. The latter could be handled and demonstrated more easily than the specimens stored in alcohol.

\section{FORMS AND TEXTURE}

The three drawings of figure 1 show most of the formations of the skull. Figure 2 shows the same views with a superimposed grain pattern based on the foregoing material. However, before these summary drawings could be made, a number of skull specimens marked with split-lines had to be examined. Although careful study showed that certain form and texture relationships recurred in different regions, no clue to interpretation immedi- ately suggested itself. This recognition of a few recurring patterns was ineffectual until a fresh approach was used.

Three skulls that had been sawed to show the interior of the braincase were first painted neutral grey. Exterior and interior surface forms were then marked by painting them different colors, each color corresponding to a different shape or form. Initially, the colors were used merely to distinguish planar regions, elevated (convex) areas, and depressed (concave) surfaces. Later, further distinctions were made: elongate ridges were considered apart from domes and saddle-shaped areas; troughs were distinguished from circular basins, and so on. Some of the finer distinctions proved unnecessary when the corresponding grain patterns were compared; others, however, were consistently correlated with differences in grain patterns.

As the split-line skulls were examined, seven patterns of grain, corresponding with seven skull forms, emerged as apparently the most basic. These seven patterns included almost all the surface of the skull. Many of the forms in the seven categories of the new grouping have standard anatomical names, but there are others that have no specific names.

Since the new grouping of seven forms, each with a specific grain pattern, applies to so many forms, both named and unnamed, it will be important to develop a new terminology in which both form and texture are indicated, a terminology that cannot be confused with standard anatomical nomenclature.

The seven form-texture types are diagrammed in figure 3 ; the illustration also includes an eighth type to be treated separately. Each has a name and a code letter that will identify patterns in the photographic illustrations. In the following discussion of these types, conventional anatomical terms such as "eminence," "crest," and "fossa" are avoided, since they are generalized descriptive terms that apply equally to bones, viscera, and surface anatomy. The present need, rather, is for terms relating specifically to bone structure and denoting both the physical forms and the grain architecture associated with each. Thus, "ridge" and "trough" will be 

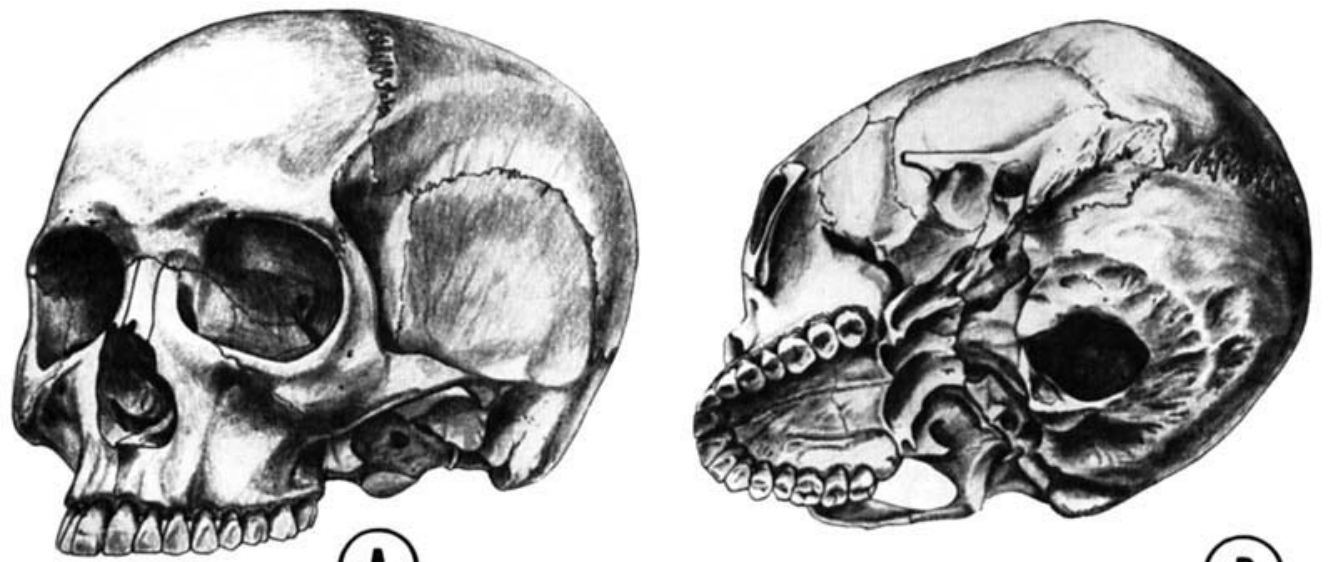

(A)

(B)

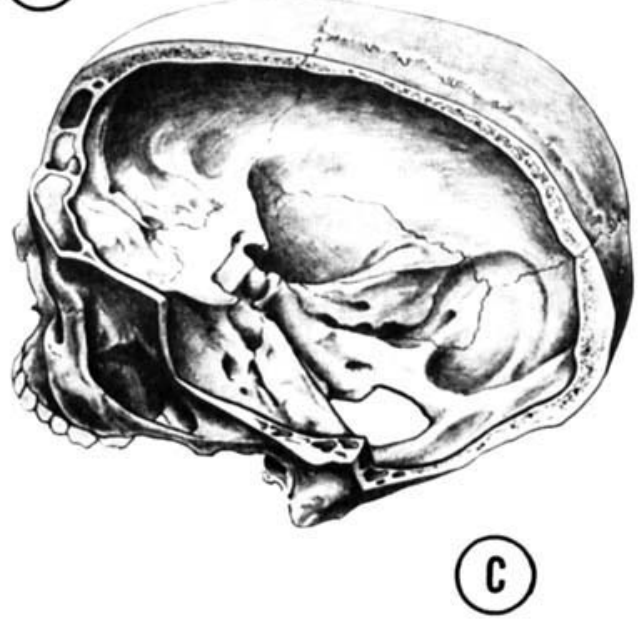

Fig. 1 Three views of the adult skull showing by shading the principal forms, apart from those of the nasal cavity. A, intact skull; B, right zygomatic arch cut away; C, much of left side of cranial vault removed to show interior.

used to designate both the specific forms they describe and the underlying microorganization of the forms.

B, Braincase cortex (fig. 3) shows a dispersed pattern of random lines. This pattern is found on both convex and concave surfaces that have relatively large radii of curvature; for example, in most of the exterior and interior of the skull vault.

$\mathrm{P}$, Plane surfaces show either a parallel grain or, in triangular areas, a radiating, fanlike pattern of grain.

$\mathrm{R}$, Ridges and crests show the most clearly expressed pattern. They may be plano-convex elevations (like the "barrel arches" of architecture), elliptical eleva- tions, or saddle-shaped elevations. These forms may lie on either plane or moderately curved surfaces. In each instance, the grain direction shown by split-lines runs parallel to the less convex axis of an elevation; that is, parallel to the crest of the ridge. The grain runs parallel to the ridge whether the top of the ridge is straight, convex, concave, or sigmoid - but the grain is always perpendicular to that cross section of the ridge having the smallest radius of curvature. (This is true even for the occipital condyle, as shown in figs. 2, 5 , where the ridge lies obliquely across the length of the condyle.) 

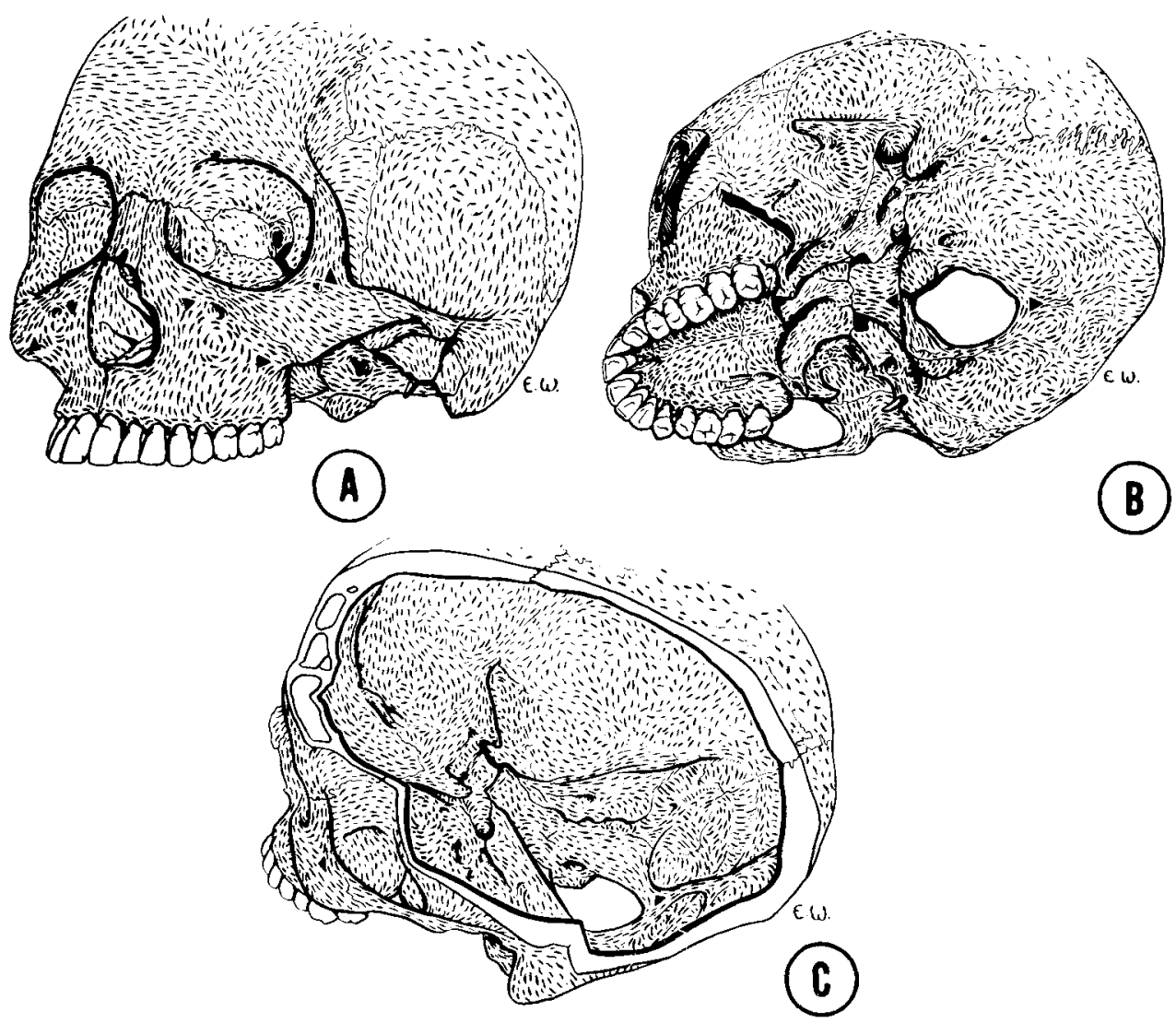

Fig. 2 The same three views of the skull showing the common texture pattern of the cortical bone as revealed by split-lines.

$\mathrm{T}$, Troughs are elongate, shallow trenches having a transverse grain; their margins, however, often show elongate ridge patterns. Some troughs are elongate plano-concave depressions. Others are doubly concave, and here the radius of curvature is markedly different for the two axes. A minor ridge within a trough will show the characteristic elongate ridge pattern, and the interrupted transverse trough pattern will show on one or both sides of the ridge. This suggests that the ridge pattern is in some sense "dominant" to the trough pattern.

C, Concavities are basin-like depressions with an irregular series of concentric circles, whorls, or spirals of grain pattern. If the concavity is elongate, so that its deepest part is like a trough, the base of the concavity will be marked by the transverse pattern of split-lines characteristic of troughs: this suggests that the trough pattern is dominant to the concavity pattern. Again, minor ridges running through a concavity show the elongate ridge pattern that seems to be dominant to both the trough and concavity patterns.

E, Unsupported free edges such as flanges, fins, and margins of thin foramina have a simple pattern of grain that parallels the free edge.

$\mathrm{S}$, Spines, hooks, and sharp processes have a grain pattern that follows the shape of the part and converges to an apex.

A final, eighth category, D, Discontinuities is, to some extent, a convenient catchall for miscellaneous forms, an essential one, however, for a balanced discussion of skull mechanics. In each of 
the foregoing seven forms, grain is related in a rather specific way that is suggestive of some structural significance. Discontinuities, in some instances, are merely a combination of edges and spines, already listed, together with foramina and sharp grooves. Although about 50 discontinuities are listed below, their characteristics can best be considered in a later part of this paper.

\section{A classification of form-textures of the skull}

With this introduction to the different categories of form and texture relationships in the skull, a classification of the principal forms of the skull will be given. This will demonstrate how inclusive the relations are. In deriving this catalog of forms, from six to ten specimens (or nearly double these numbers if rights and lefts are distinguished) were studied. The grain patterns are those of fully adult skulls. Growth patterns with markedly different textures predominate in the fetus, infant, and child (Ahrens, '36); these patterns usually radiate from ossification centers. In time, specializations of form and texture give rise to definitive adult patterns. A certain amount of variability is found: concavities in one specimen may show as troughs in another, or small plane areas of one specimen may show as a random pattern in the next; the pattern common to one area may encroach on an adjacent one; an infantile pattern may persist in a localized region. However, most forms are found consistently, and extreme variations are rare. The following classification arbitrarily lists patterns that appear to be most common, and only a few variants are mentioned. Re-
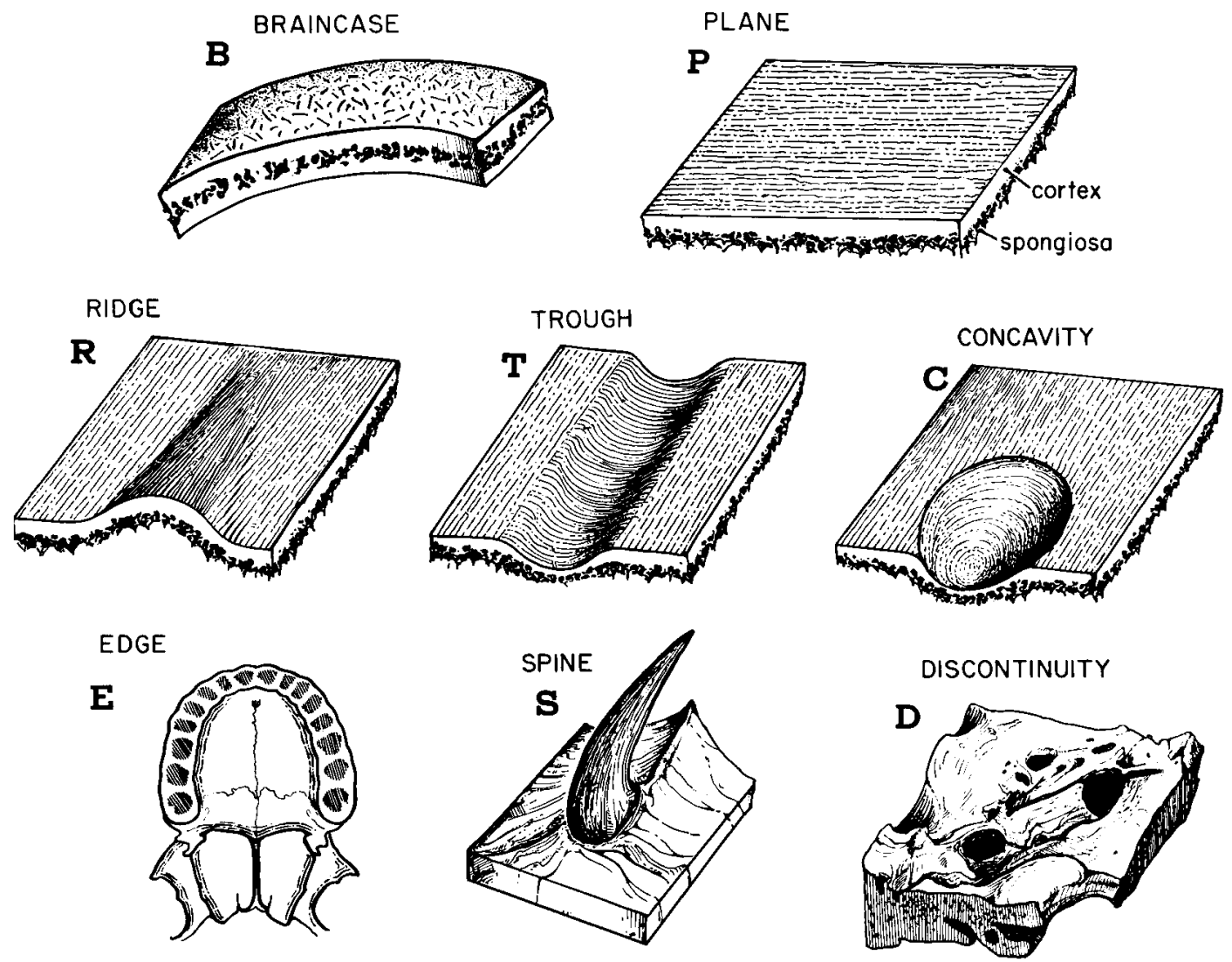

Fig. 3 Diagrams of eight form-textures with their predominant grain direction. All but the last have a characteristic grain pattern. With each sketch is a name and a code letter. 
presentative illustrations of the texture in different regions will also testify to the fact that anatomical structures in the skull do have a specified form and texture. Following the classification, this paper discusses the associated forms and textural arrangements in terms of their architectural or mechanical implications.

Most features of the skull surface are classified below with regard to both the form and the direction of the grain texture of the cortical bone. Figure 4 illustrates the principal regions of the skull surface that show random braincase structure, planes, and concavities. Figure 5 shows the loca- tions of ridges and spines, and figure 6 shows where troughs and edges are found. The capital letters at the head of each category are the code letters used in labeling the photographs. The figure numbers in parenthesis after the name of each part refer to figures that illustrate the texture involved. If a structure illustrated in a photograph is labelled with a code letter, that letter in brackets follows the figure number, as: (fig. $7[\mathrm{C}]$ ).

B - Braincase (figs. 2A, 2B, 2C, 3, 4): the random pattern found in most of the skull vault externally between the frontal eminences and the superior nuchal line,

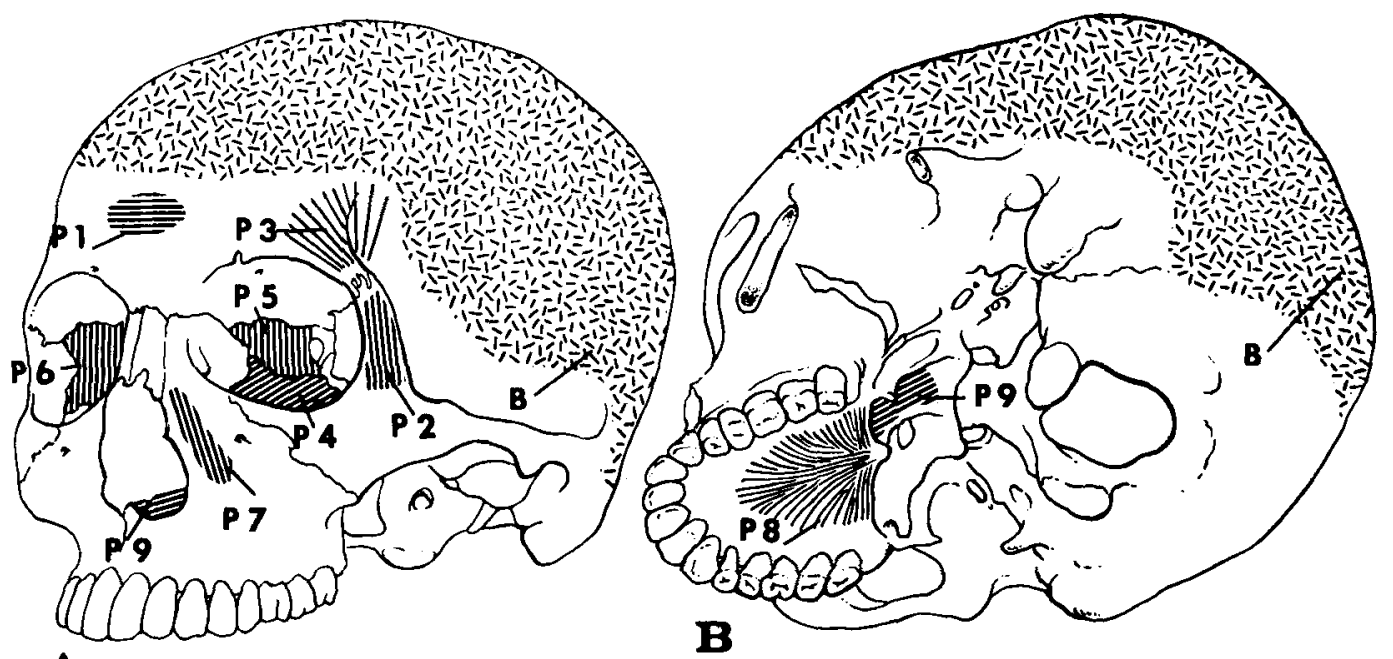

$\mathbf{A}$

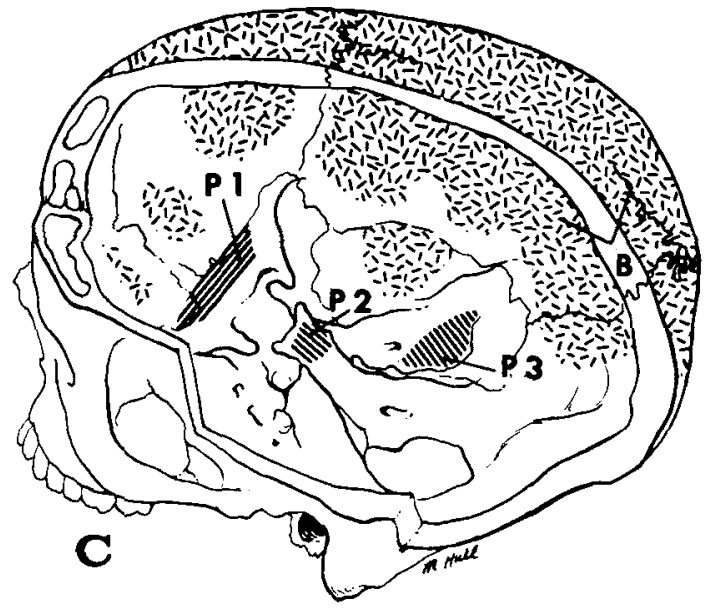

Fig. 4 Areas of the skull surface occupied by braincase texture, B; and by planes, P. The code numbers P1, P2, and so on correspond to the list of planes in the text. 
extending laterally into the temporal fossae; the interior of the skull vault except in the sagittal crests and fossae; also in localized areas of the anterior and middle cranial fossae of the base of the skull (figs. $4[\mathrm{C}], 8[\mathrm{~B}], 10[\mathrm{~B}])$.

$\mathrm{P}$ - Planes and relatively flat surfaces (figs. 3, 4):

\section{Exterior of the skull.}

1. Supraglabellar plane showing transverse grain (fig. 2A) above and between the superciliary arches; sometimes a random braincase pattern (fig. 4).

2. Frontal process of zygoma, superficial surface (figs. 2A, 2B, 8 ).

3. Triangular area anterior to superior temporal line, partly superior to lateral orbital margin (figs. 2A, $8[\mathrm{P}]$ ).

4. Maxilla forming floor of the orbit, sometimes random braincase pattern (fig. 2A).

5. Orbital surface of the ethmoid bone (fig. 2A).

6. Orbital surface of the greater wing of the sphenoid bone (fig. 2A).

7. Nasofrontal process and body of maxilla between margins of orbit and piriform aperture (fig. 2A).

8. Posteromedial part of the hard palate, palatine, and maxillary bones (figs. 2B, $9[\mathrm{P}])$.

9. Perpendicular plate of vomer (figs. 2A, 2B).

10. Perpendicular plate of ethmoid bone (no fig.).

II. Interior surface of the cranial cavity.

1. Superior surface of the lesser wings of the sphenoid bone; the plane between the two lesser wings (figs. $2 \mathrm{C}, 10[\mathrm{P}]$ ).

2. Dorsum sellae (fig. 2C).

3. That portion of the petrous part of the temporal bone between its posterior margin and the aqueductus vestibuli (fig. $2 \mathrm{C}$ ).

4. Localized areas of the sphenoid, temporal, and parietal bones in the lateral part of the skull vault (fig. $2 \mathrm{C}$ ).

R-Ridges AND CRests (figs. 3, 5):

I. Exterior of the shull.

1. Area across frontal bone between right and left frontal eminences (figs. 2A, $5 \mathrm{~A}[1])$.

2. Superciliary arches (figs, 2A, 5A [2]).

3. Superior orbital margin from frontosphenoidal process of the zygomatic bone to supraorbital notch; also from the notch to the nasal process of the maxilla (figs. 2A, 5A [3]).

4. Portion of the inferior and lateral margin of the orbit formed by the zygomatic bone (figs. 2A, 5A [4], $8[\mathrm{R}]$ ).

5. Bridge of nose and facial surfaces of nasal bones, extending to adjacent naso- frontal process of maxillae, usually a saddle-shaped ridge (figs. 2A, 5A [5], $8[R]$ ).

6. Lacrimal crest and adjacent slopes of the bone (fig. 2A, 5A [6]).

7. The whole alveolar part of the maxilla, below the nasal aperture from the region of the first and second molar teeth on the side across the midline to the opposite side (figs. 2A, 5A [7], $8[\mathrm{R}]$ ).

8. Posterolateral aspect of the body of the maxilla, anterior and parallel to the pterygopalatine fissure (figs, 2B, 5B [8]).

9. Lower part, external face of the body of the zygomatic bone, from the maxillary process to the temporal process (figs. $2 \mathrm{~A}$, 5A [9]).

10. Crest of maxilla between lower part of the zygomatic process and first and secand molar teeth (figs. 2A, 2B, 5A [10], $8[R])$.

11. Outer surface of zygomatic process of temporal bone (figs. 2A, 5A [11], 8 [R], 11 [R]).

12. Articular tubercle of temporal bone along its whole width - a saddle-shaped ridge (figs, 2B, $9[R]$ ).

13. Lateral surface of mastoid process - a vertical ridge (figs. $2 \mathrm{~A}, 2 \mathrm{~B}, 2 \mathrm{C}, 11[\mathrm{R}]$ ).

14. Ridge at lower border of zygomatic root, superior to external acoustic meatus, from postglenoid tubercle to mastoid process (figs. 2B, 11).

15. Transverse ridge - sometimes a plane area - on inferior surface of greater sphenoid wing, anterior to the foramen ovale and between the base of the lateral pterygoid lamina and the articular eminence (figs. 2B, 9).

16. Basal surface of petrous part of the temporal bone anterior to the carotid canal (figs. 2B, 9).

17. Basilar part of occipital and sphenoid bones, between the vomer and the crest of the anterior margin of the foramen magnum (figs. $2 B, 9[R]$ ).

18. Articular surfaces of the occipital condyles; grain runs obliquely across the narrow dimension in a mediolateral direction (figs. $2 \mathrm{~B}, 9[\mathrm{R}]$ ).

19. Anterior margin of foramen magnum and anterior condylar crest (figs. 2B, 9).

20. Lateral postcondylar and posterior margins of foramen magnum (fig. 2B).

21. Superior, inferior, and medial nuchal lines (fig. 2B).

22. Ridge between groove for occipital artery and digastric fossa; juxtamastoid eminence, Taxman, ('63) (no fig.).

II. Interior of the cranial cavity.

1. Frontal crest anterior to the crista galli and foramen cecum; also, continuing ridges at the right and left of the sulcus for the superior sagittal sinus, especially on the frontal and occipital bones (fig. $2 \mathrm{C})$. 


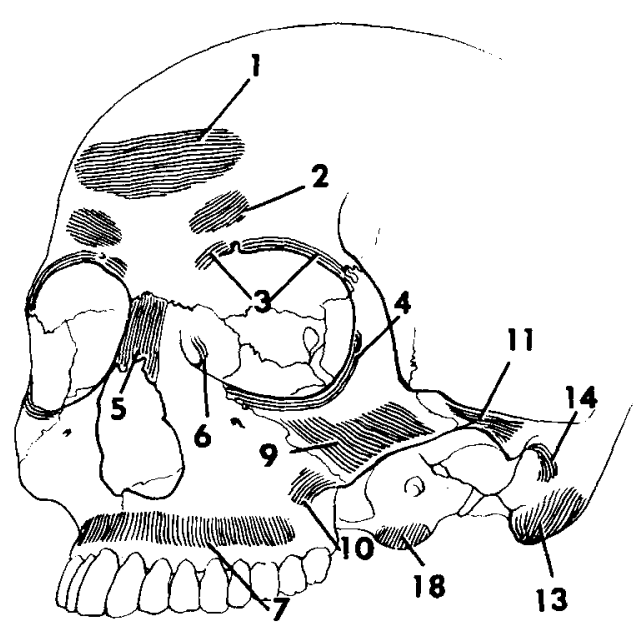

$\mathbf{A}$
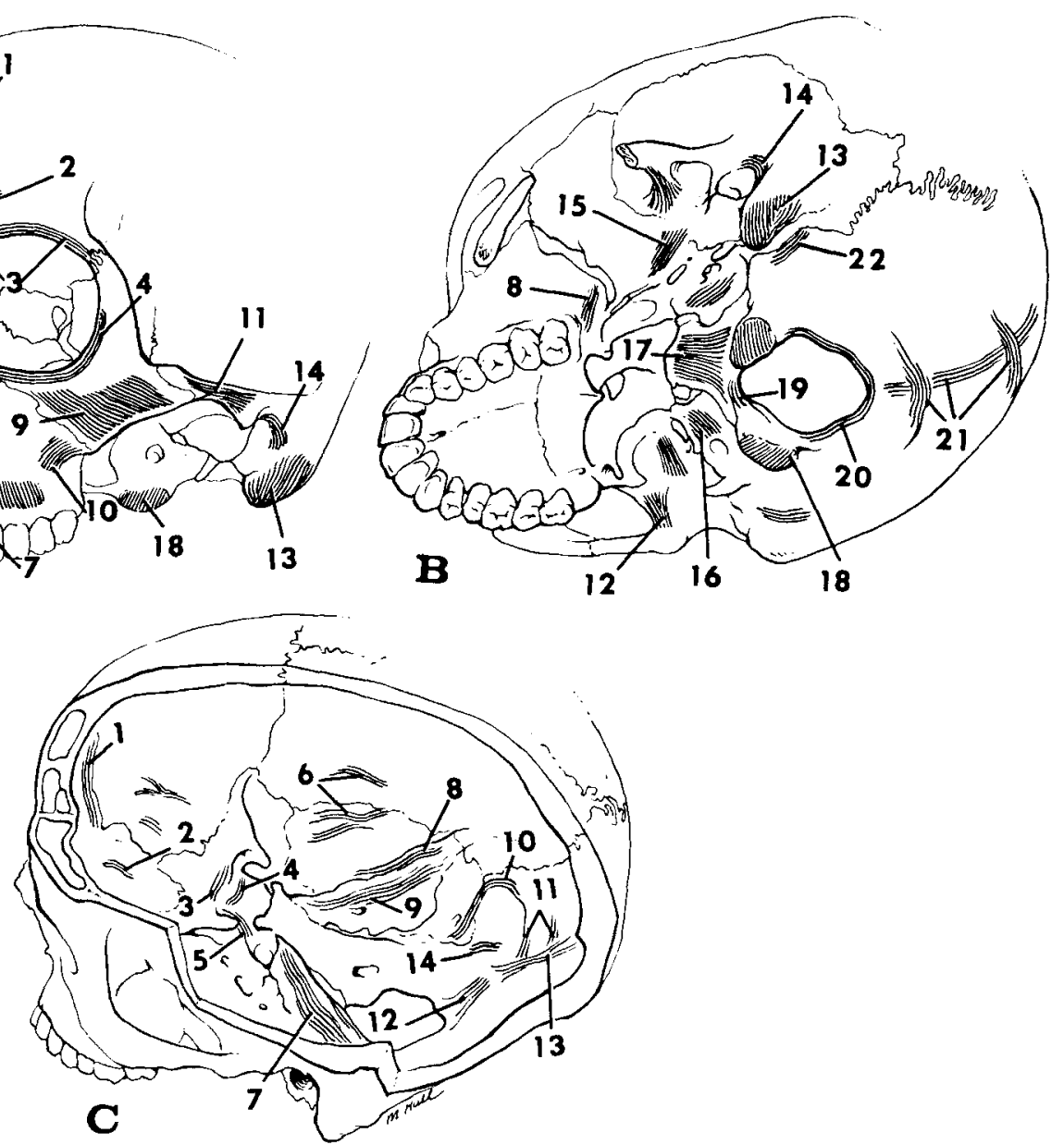

Fig. 5 Areas of the skull surface occupied by ridge form-textures - R. Numbers correspond to the list of ridges in the text.

2. Ridges, usually longitudinal, between the digital fossae of the orbitobasal plate of the frontal bone (figs. 2C, 10 [R]).

3. Transverse ridge anterior to chiasmatic groove, joining anterior clinoid processes (figs. 2C, 10).

4. Tuberculum sellae, transverse pattern between chiasmatic groove and hypophyseal fossa (figs. 2C, $10[\mathrm{R}]$ ).

5. Parasagittal ridges on sphenoid body between the floor of the sella turcica and the carotid grooves (fig. 2C).

6. Ridges between digital fossae of the middle cranial fossa (figs. $2 \mathrm{C}, 10$ ).

7. Ridges along the length of the anterior surface of the petrous part of the temporal bone, including the arcuate eminence (figs. 2C, $10[R]$ ).

8. Ridges on the superior margin of the petrous bone, bordering the superior petrosal sinus (figs. 2C, 10).
9. Posterior face of the petrous part of the temporal bone, superior to the aqueductus vestibuli (fig. $2 \mathrm{C}$ ).

10. Ridge posterior to the sigmoid sulcus (fig. 2C).

11. Ridges above and below the sulcus for the transverse sinus (fig. 2C).

12. Median sagittal crest between right and left cerebellar fossae (fig. 2C).

13. Crest between the right and left posterior cerebral fossae (fig. 2C).

14. Minor ridges in the floor of the cerebellar fossae, inconstant (fig. 2C).

(Commentary: as in Langer's (1861) splitlines in skin, three texture tracts associated with ridges and planes will merge, two by two, to form a triradiate pattern with a tiny triangular area or node at the focus. These are shown as black trigones in figure 2 as follows: figure $2 \mathrm{~A}$, (1) on the maxilla medial to the infraorbital 
foramen, (2) on the anterior face of the zygomatic process of the maxilla, and (3) on the external surface of the zygoma at the junction of the frontal process with the body; figure 2B, the exterior basal aspect of the skull in the midsagittal planes: (1) on the basal part of the occipital bone anterior to the foramen magnum, and (2) on the occipital squama posterior to the foramen magnum; figure $2 \mathrm{C}$, on the interior of the skull, on the midline, posterior to the foramen magnum.)

T - Troughs, grooves, furrow, gutters, or trenches (figs. 3,6 ):

I. Exterior of the skull.

1. Walls of the nasolacrimal canal proper, but not the continuous nasolacrimal fossa of the lacrimal bone anterior to the lacrimal crest (no fig.).
2. Posterior surface of the body and frontal process of the zygomatic bone (bounding the temporal fossa); trough pattern, both above and below the level of the infraorbital fissure (figs. 2A, 2B, 2C, $6 \mathrm{~A}[\mathrm{~T} 2], 8[\mathrm{~T}])$.

3 . Groove on the upper surface of the junction of the anterior root of the zygomatic arch with the adjacent squama of the temporal bone - the groove acts as a pulley for the posteriormost fascicles of the temporalis muscle (figs. 2C, $11[\mathrm{~T}]$ ).

4. Infratemporal fossa between lateral pterygoid wing and infratemporal crest (figs. 2B, $9[T]$ ).

5. Gutters on the palate between the palatal and alveolar processes of the maxilla the anterior and superolateral arches of the palatal vault (figs. $2 \mathrm{~B}, 9[\mathrm{~T}]$ ).

6. Roof of the nasal cavity between the vomer bone and the medial pterygoid

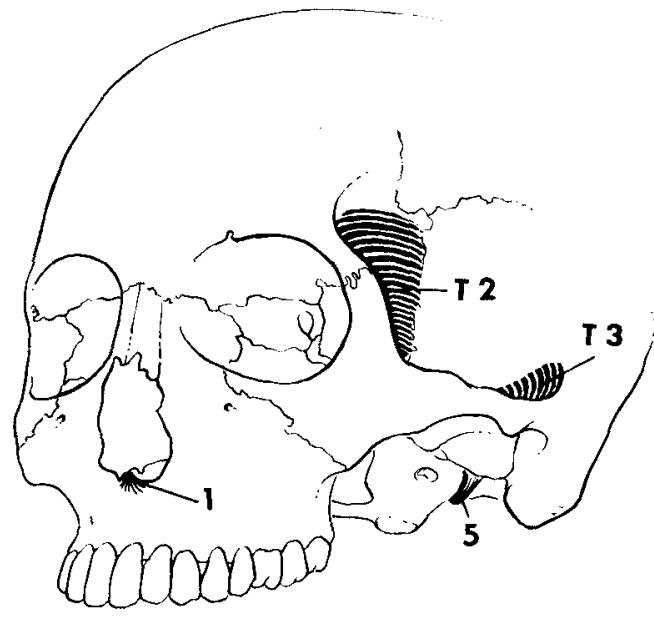

$\mathbf{A}$
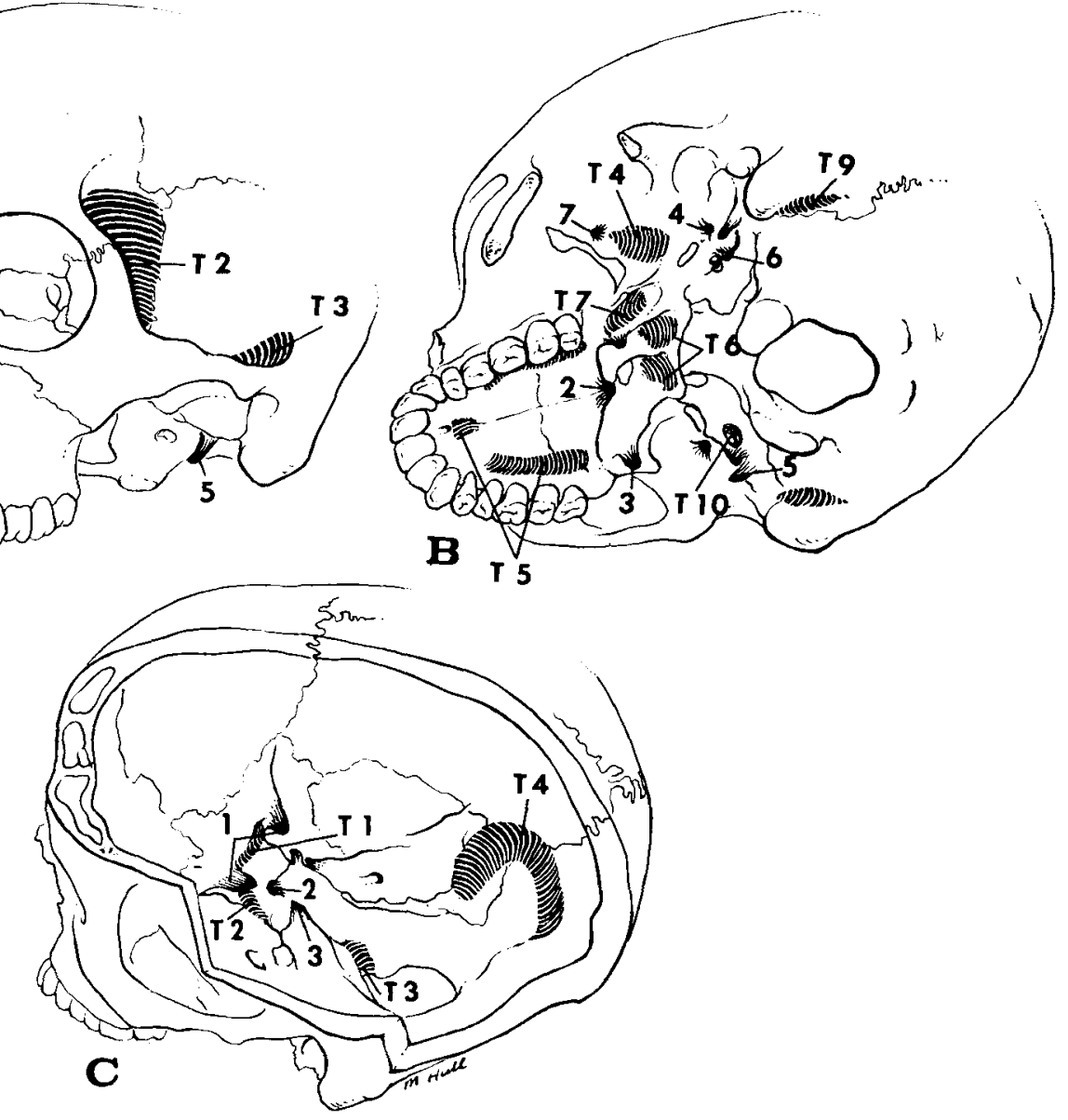

.

Fig. 6 Areas of the skull surface with the form and textures of troughs - T, and spines - S. The troughs are numbered T1, T2, and so on to correspond to the list of troughs. The other numbers refer to spines as listed. 
plate and vertical part of the palatal bone (fig. 2B).

7. Inferior part of pterygoid fossa; transverse grain across fossa (fig. 2B); grain pattern in superior part of the fossa is partly or wholly that of a concavity (C) (figs. 2B, $9[\mathrm{C}]$ ).

8. Inferolateral border of the floor of the nasal cavity (no fig.).

9. Posterior digastric fossa (fig. 2B).

10. Concave wall of the carotid canal (fig. 2B).

II. Interior of the cranial cavity.

1. Hypophyseal fossa (fig. $10[\mathrm{~T}]$ ); sometimes the posterior portion or the whole is a concavity (C) (figs. $2 \mathrm{C}, 9$ ).

2. Wall of carotid canal and of the carotid groove on the body of the sphenoid bone lateral to the sella turcica (figs. 2C, 10).

3. Grain tracts on lowest part of the clivus near the foramen magnum from the medial side of one condyle to the other (figs. 2C, 10); although most of the clivus to the dorsum sellae is concave, ridge tracts from the sides of the foramen magnum above the hypoglossal canals converge to form a dominant ridge-type sagittal pattern of grain. The dorsum sellae proper has a plane structure; its upper margin shows an edge pattern, and the posterior clinoid processes are spines.

4. Transverse and sigmoid sulci, except in the region nearest the jugular foramen (fig. 2C).

C - Concavities, concave depressions, rounded fossae, bowls, or basins (figs. $2,7)$ :

I. Exterior of the skull.

1. Lacrimal fossa in the superiorlateral orbital roof (fig. 2A).

2. The facial surface of the maxilla inferior to the infraorbital foramen (figs. $2 \mathrm{~A}$, 7A [C2]).

3. Canine fossa, inconstant (no fig.).

4. Variable fossae in the anterior part of the palatal arch between the alveolar process, at the cuspid or bicuspid tooth, and the midline (figs. 2B, $9[\mathbf{C}]$ ).

5. Upper part of the pterygoid fossa (figs. 2B, $9[\mathrm{C}]$ ).

6. Mandibular fossa of temporal bone, sometimes troughlike (fig. 2B).

7. Bilateral areas on the inferior surface of the basilar process of the occipital bone, anterior to the roots of the occipital condyles, inconstant (no fig.).

8. Fossa of the posterior condyloid canal (fig. 2B).

9. Concave anterior wall of jugular fossa (fig. 2B).

10. Fossae on the base of the occipital squama for muscular attachment of suboccipital and semispinalis capitis $\mathrm{mm}$ (fig. 2B).
II. Interior of the cranial cavity.

1. The deeper digital fossae at the anterolateral margins of the anterior cranial fossa (figs. $2 \mathrm{C}, 10[\mathrm{C}]$ ).

2. Floor of hypophyseal fossa (fig. 2C), sometimes a transverse trough with an anteroposterior grain (fig. $10[\mathrm{~T}]$ ).

3. Superior concave surface of the greater wing of the sphenoid bone near the superior orbital fissure - contacts the anterior pole of the temporal lobe (figs. $2 \mathrm{C}$, $10[\mathrm{C}]$ ).

4. Cerebellar fossa of the posterior cranial fossa - often crossed by a trough or ridge (fig. $2 \mathrm{C}$ ).

5. About $2 \mathrm{~cm}$ of the sigmoid sulcus nearest the jugular foramen, below the overhanging rear border of the petrous part of the temporal bone (fig. 2C).

E-EDGEs, thin flangelike or finlike plates, or keels with unsupported free edges (figs. 3,7 ):

I. Exterior of the shull.

1. Lateral margin of nasal (piriform) aperture on the face bounded by the maxillae, but not including the free ends of the nasal bones (figs. 2A, 2B, 7A [1]).

2. Buccal and lingual alveolar margins -. buccal grain tract - thin in the incisorbicuspid region and wider in the molar region; wider in the lingual than in the buccal region, especially posteriorly; buccal and lingual tracts are continuous behind last molar tooth (figs. 2A, 2B, $7 \mathrm{~A}[2], 7 \mathrm{~B}, 8[\mathrm{E}], 9[\mathrm{E}])$.

3. Free margins of medial and lateral ptery. goid laminae of sphenoid bone (figs. $2 \mathrm{~A}$, 2B, 9).

4. Posterior margin of palatal process of palatine bone (figs. 2B, 9 [E]).

5. Posterior margin of the vertical plate of the vomer bone (fig. 2B).

6. Anterior, superior, and lower margins of infraorbital fissure (figs. $2 B, 9[E]$ ).

7. Anterior border of the bony nasal septum - ethmoid, vomer (fig. 2A).

8. Margins of foramina with thin borders (as foramen ovale); in oblique foramina (as internal acoustic meatus and infraorbital foramen), one side of the foramen has a specialized margin (figs. 2A, 2B, 2C, 9 [E]].

9. Free edge of lateral wall of the nasolacrimal canal (no fig.).

10. Free margins of the nasal conchae (no fig.).

II. Interior of the cranial cavity.

1. Margins of crista galli, ethmoid (fig. 2C).

2. Posterior border of lesser wing of sphenoid, lateral to the anterior clinoid process (figs. 2C, $10[\mathrm{E}]$ ).

3. Lower, outer margin of superior orbital fissure - greater wing of sphenoid (fig. $2 \mathrm{C}$ ). 


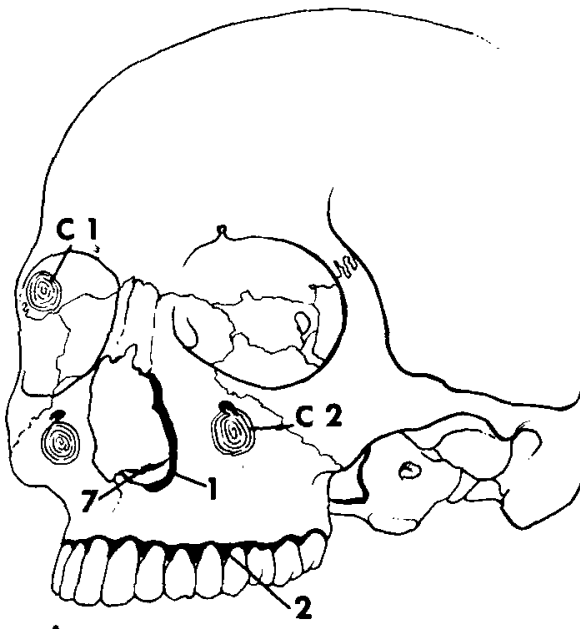

$\mathbf{A}$
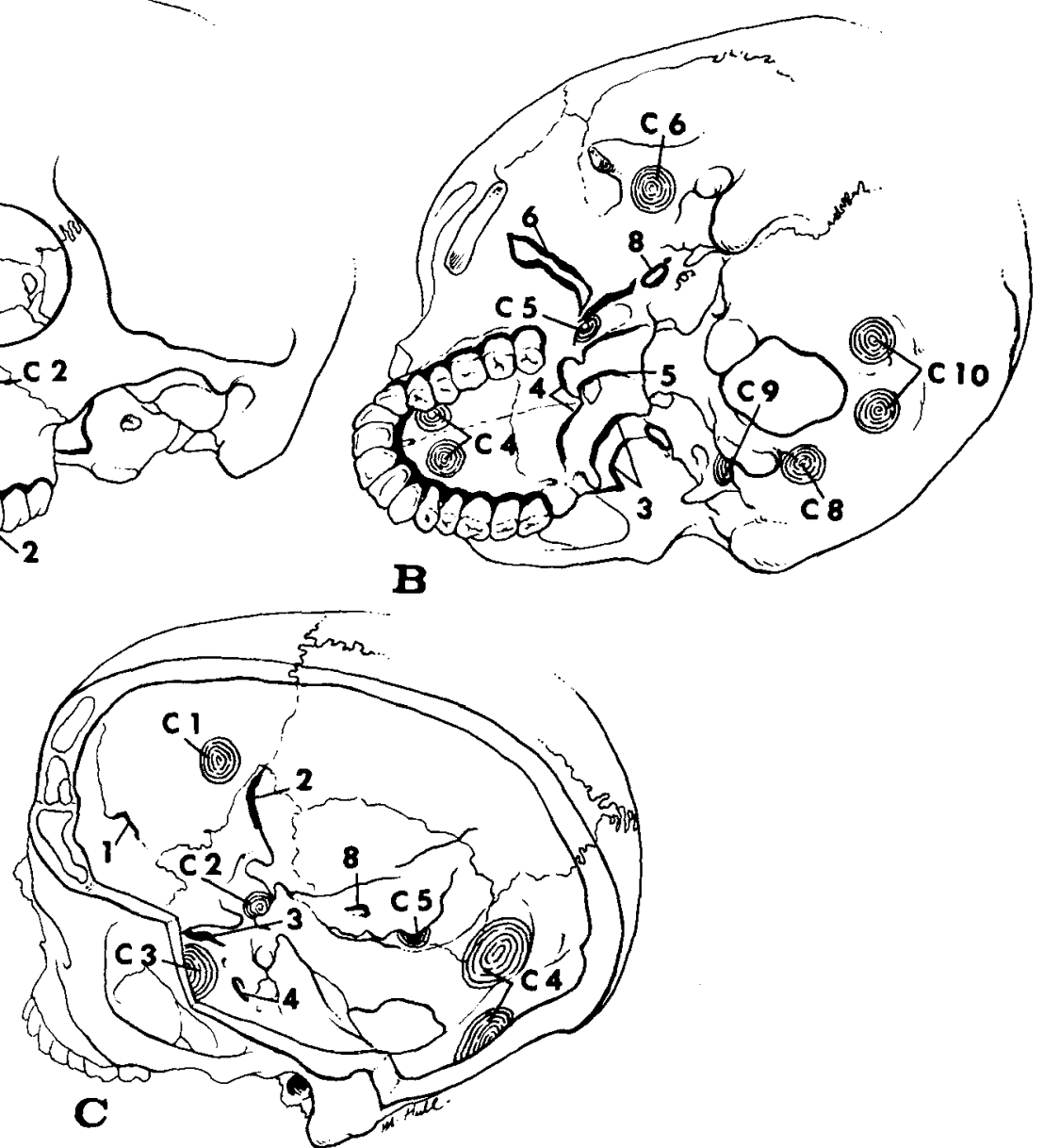

Fig. 7 Areas occupied by edges - $\mathrm{E}$ (heavy black lines) and by concavities - $\mathrm{C}$ (concentric circles). The edges are designated by numbers corresponding to the list of forms. The concavities are coded $\mathrm{C} 1, \mathrm{C} 2$, and so on.

4. Margins of foramina with thin edges, as foramina ovale, (fig, 2C) and cf. I-8, above.

S -- SPINEs, hooks, or sharp processes (figs. 3, 6):

I. Exterior of the skull.

1. Anterior nasal spine, maxillae (figs. 2A, $6 \mathrm{~A}[1])$.

2. Posterior nasal spine, palatine bones (figs. 2B, $9[S]$ ).

3. Pterygoid hamulus (fig. 2B).

4. Spine of angle, sphenoid (fig. 2B).

5. Styloid process, temporal bone (fig. 2B).

6. Spine of vaginal process, tympanic bone (fig. 2B).

7. Spine of infratemporal crest, sphenoid (fig. 2B).
II. Interior of the skull.

1. Anterior clinoid process (figs. 2C, 10 [S]).

2. Posterior clinoid process (fig. 2C).

3. Apex, petrous part of temporal bone (figs. 2C, 10 [S] ).

D-Discontinuities: sharp edges, holes, or foramina; projections; surfaces meeting at sharp angles: the following list in part includes structures of the previous list when sharp breaks in surface continuity or irregular congeries of forms are close together. The discontinuities listed below are not specifically identified in the illustrations (fig. 3):

I. Exterior of the skull.

1. Supraorbital notch or foramen (figs. 1A, 2A). 


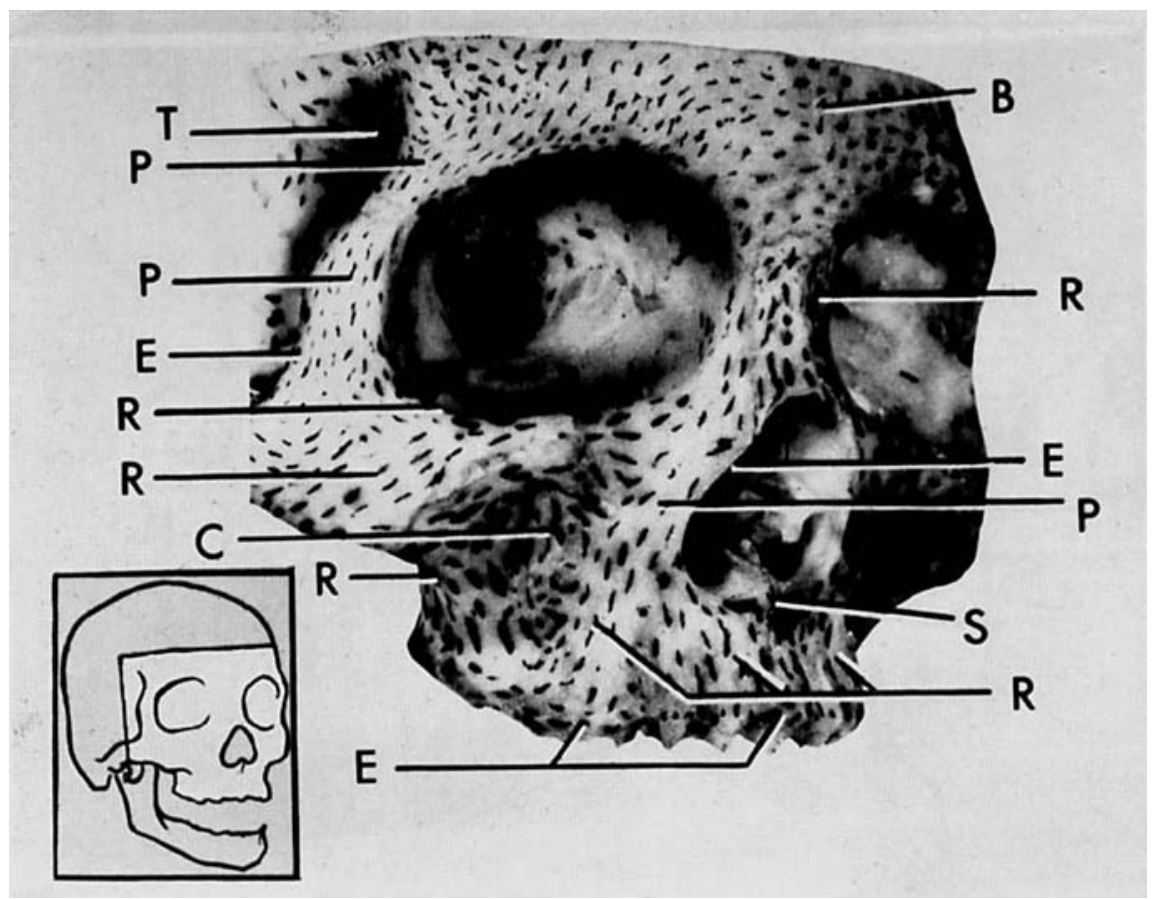

Fig. 8 Photograph of the facial view of a decalcified skull with split-lines. Code: B braincase, $\mathrm{C}$-- concavity, $\mathrm{E}$ - edge, $\mathrm{P}$ - plane, $\mathrm{R}$ - ridge, $\mathrm{S}$ - spine, and $\mathrm{T}-$ trough.

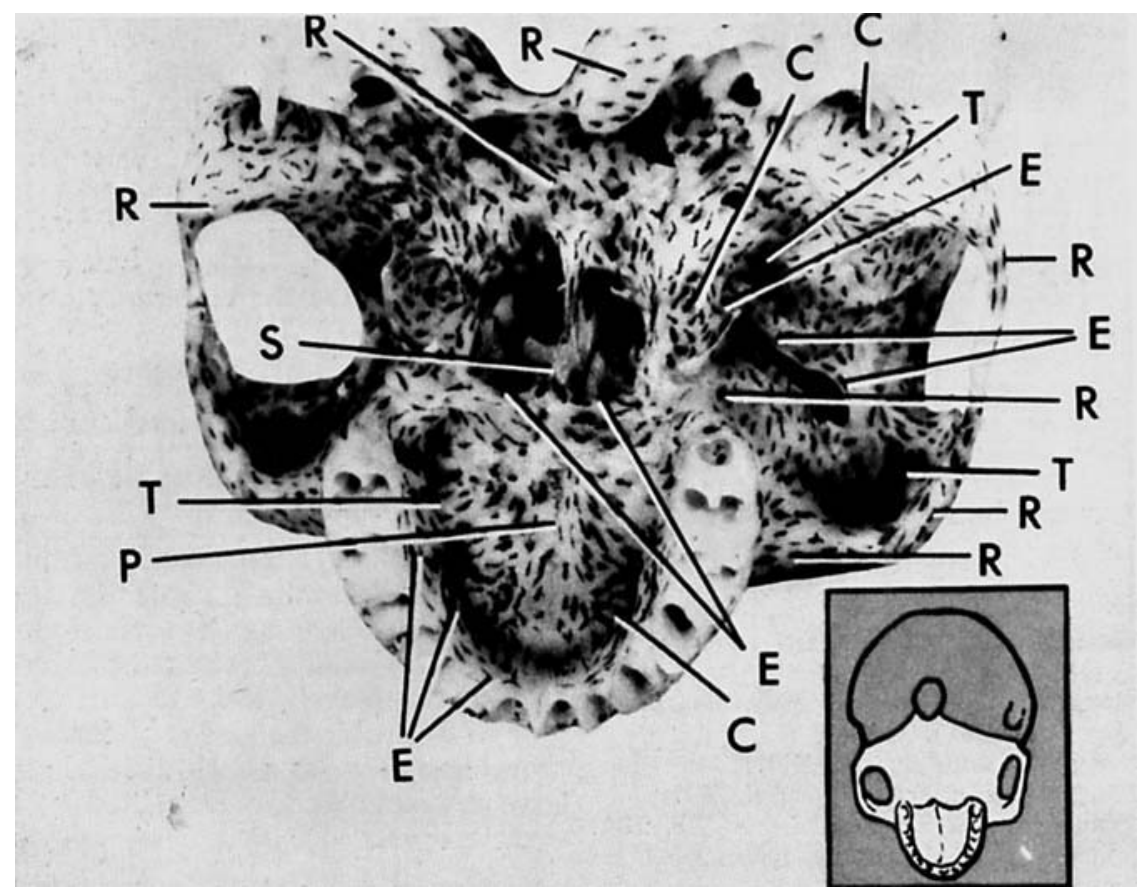

Fig. 9 Photograph of split-line preparation of anterior-basal region of the skull. Code: $\mathrm{C}$ - concavity, $\mathrm{E}$ - edge, $\mathrm{P}$ - plane, $\mathrm{R}$ - ridge, $\mathrm{S}$ - spine, $\mathrm{T}-$ trough. 


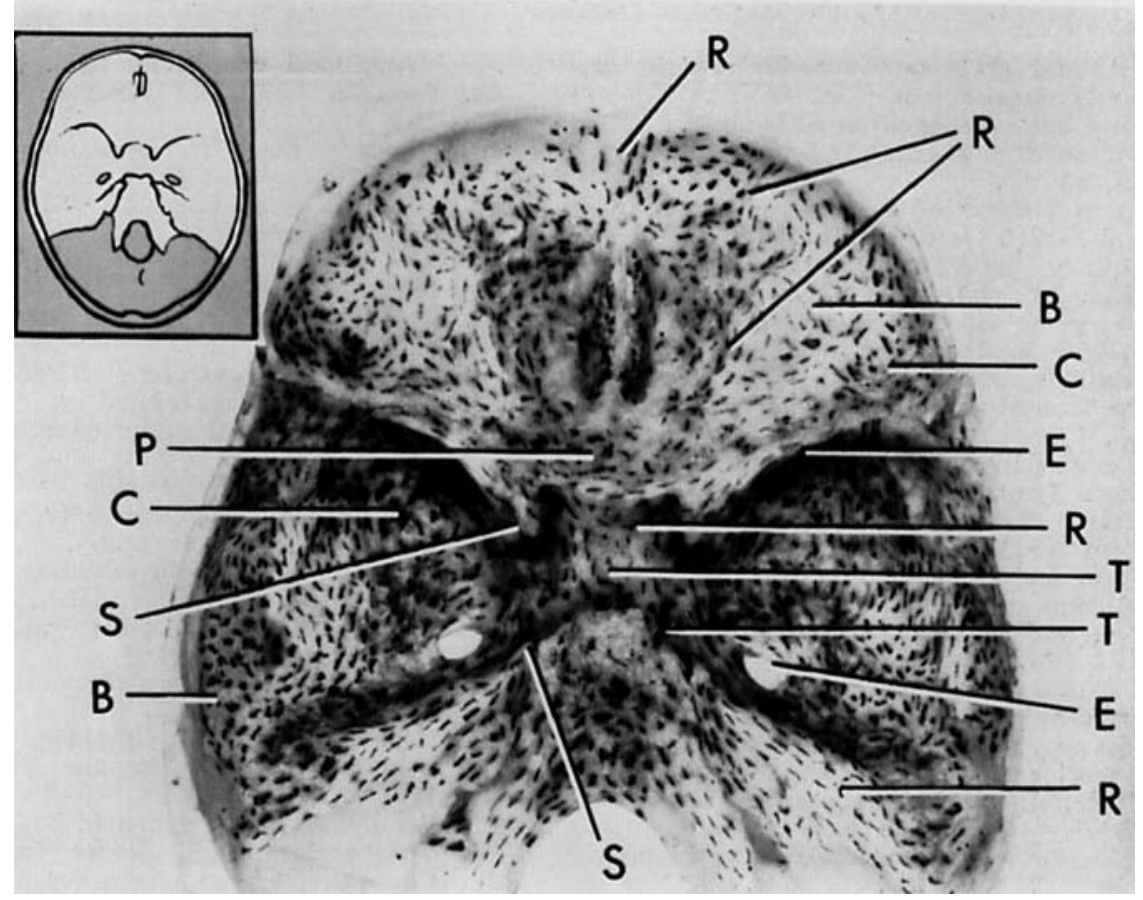

Fig. 10 Photograph of a split-line preparation of anterior portion of interior-basal aspect of the skull. Code: B - braincase, C-concavity, E-edge, P-plane, $\mathrm{R}$ - ridge, and $\mathrm{T}$ - trough.

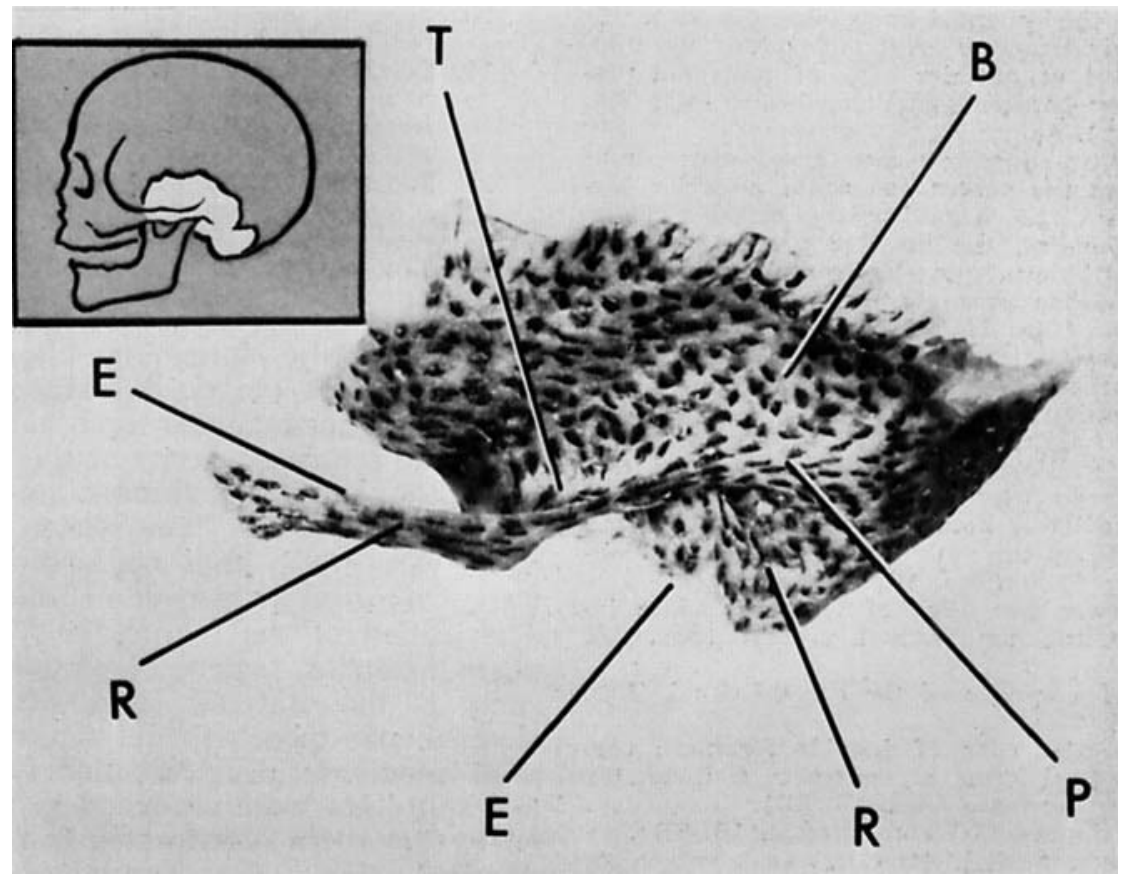

Fig. 11 Photograph of lateral aspect of temporal bone, split-line preparation. Code: B braincase, $\mathrm{E}$ - edge, $\mathrm{P}$ - plane, $\mathrm{R}$ - ridge, and $\mathrm{T}$ - trough. 
2. Lacrimal crest and anterior margin of the lacrimal sulcus (figs. $1 \mathrm{~A}, 2 \mathrm{~A}$ ).

3. Thin bone of the ethmoid bone; air cells and partitions; ethmoidal foramina (figs. 1A, 2A, 7).

4. Sharp borders of the infraorbital groove and fissure (figs. 1B, 2B, 7,8 ).

5. Inferior border of supraorbital fissure (figs. 1A, 2A).

6. Sharp margin, superior and lateral borders of the orbital aditus from the supraorbital notch laterally to the midlevel of the frontal process of the zygoma (figs. 2A, 7).

7. Superior margin of the infraorbital foramen (figs. 1A, 2A, 7).

8. Sharp edge bordering nasal aperture, from nasal bones to anterior nasal spine (figs. 1A, 2A, 7).

9. Margins of the tooth sockets (fig. 8).

10. Posterior margin of the incisive foramen (figs, 1B, 2B, 9).

11. Posterior border of palatine bone from posterior nasal spine to pyramidal process of palatine bone (figs. 1B, 2B, 9).

12. Posterior border of vomer bone; also articulation with sphenoid bone (figs. 1B, 2B).

13. Posterior edge of medial pterygoid plate (figs. 1B, 2B, 9).

14. Inferior and posterior edges of lateral pterygoid lamina; pterygoid spine of Civinini (figs. $1 \mathrm{~B}, 2 \mathrm{~B}, 9$ ).

15. The crest separating scaphoid from pterygoid fossae (no fig.).

16. Sharp margins of the spine of the angle of the sphenoid bone (figs. 1B, 2B).

17. Infratemporal crest and spine (fig. 2B).

18. Keel at anterior edge of pterygoid process bordering pterygopalatine fossa (no fig.).

19. Sharp superior border of zygomatic arch; also the continuous acute posterior border of the frontal process of the zygoma, including the angular process and the continuation to the frontal bone as the anterior part of the superior temporal line (figs. 1A, 2A, 7).

20. Free margin of the tympanic bone at the external acoustic meatus; also continuing sharp edge behind the postglenoid tubercle (figs. 1A, 1B, 2A, 2B).

21. Miscellaneous irregular edges for tendinous attachment (masseter m.), along the lower border of the zygomatic arch and on the outer border of the mandibular fossa (figs. 1B, 2B).

22. Lower free edge of tympanic plate including the vaginal process (figs. 1B, $2 B$ ).

23. Inferior edge of the carotid canal (figs. 1B, 2B).

24. Inferior edge of jugular foramen; also vertical crest on anterior wall of the jugular fossa (figs. 1B, 2B).

25. Stylomastoid foramen (figs, 1B, 2B).

26. Anteromedial, anterior, and lateral edges of articular surface of the occipital condyle (figs, 1B, 2B).
27. Hypoglossal canal (no fig.).

28. Posterior condyloid foramen (figs. 1B, 2B).

29. Mastoid foramen, especially anterior border (figs, 1B, 2B).

30. Foramen ovale (figs. 1B, 2B, 9).

31. Foramen spinosum (figs. 1B, 2B).

32. Thin posteriormost portion of foramen magnum (figs. 1B, 2B, 1C, 2C).

33. Region of anterior palatal foramen; palatal crest (fig. 1B)

34. Foramen lacerum (figs. 1B, 2B).

35. Conchae and markings on the lateral wall of the nasal cavity (figs. 1A, 2A).

II. Interior of the cranial cavity.

1. Free edge of crista galli (figs. 1C, 2C).

2. Foramen caecum (no fig.).

3. Cribriform plate and olfactory foramina of ethmoid bone (figs. 1C, 2C, 10).

4. Posterior border of lesser wing of sphenoid (figs. 1C, 2C, 10).

5. Superior and postero-inferior margin of optic canal (no fig.).

6. Edges of posterior clinoid process and adjacent edges of dorsum sellae (figs. 1C, 2C, 10).

7. General region of sphenoid body bounded by superior orbital fissure, foramen rotundum, foramen ovale, foramen spinosum, and intracranial carotid canal (figs. $1 \mathrm{C}, 2 \mathrm{C}, 10$ ).

8. Sharp edges of hiatus of facial canal (figs. 1C, 2C)

9. Posterior border of internal acoustic meatus (figs. 1C, 2C).

10. Superior margins of aqueductus vestibuli (no fig.).

11. Posterior sharp border of petrous part of the temporal bone from apex to lateral terminus in the sigmoid sulcus (figs. $1 \mathrm{C}, 2 \mathrm{C})$.

12. Junction with sigmoid sulcus of mastoid foramen and posterior condyloid foramen (figs. 1C, 2C).

13. The grooves for the middle meningeal artery (no fig.).

Although the foregoing classification covers most of the skull surface, certain regions are not included, such as the labyrinth and tympanic cavity of the temporal bone, the paranasal sinuses, and details of the nasal cavity. The reason in some cases was simply that not enough skulls were examined to permit definitive characterization of the features involved. In other instances, regions of very thin bone, such as the ethmoid bone, after being cleaned and bleached, did not withstand even moderate decalcification. When a few split-lines were produced in very thin bone, they often deteriorated from further decalcification of surrounding thicker bony regions or from storage in alcohol. 


\section{Cortical grain and bome properties}

The tendency of decalcified cortical bone to split in a specific direction when punctured is a distinctive property of the bony matrix; although articular surfaces and minor localized areas of long bones may show round holes rather than splits, this response in the skull - as may be found at the summit of the frontal eminence - is exceptional. This results from the fact that grain patterns are intimately related to the orientation of the microscopic components of the osseous tissue. It was Benninghoff ('25) and Seipel ('48) who first showed that the direction of split-lines correlates closely with the predominant direction of the fibrous tissue of the lamellae of the bone, as in the Haversian systems. A needle penetrating decalcified bone acts like a wedge and splits the matrix a short distance in the direction of least strength. Olivo, Maj, and Toajari ('37) emphasize that although decalcified bone and intact bone have different properties, the predominant direction of split-lines in decalcified bone correlates with the direction of greatest strength in intact bone. Tensile tests of single osteons (Haversian systems) by Ascenzi and Bonucci ('64) show that the strongest osteons are those in which the fibrous bundles of successive lamellae are arranged longitudinally rather than in a strongly oblique $\left(45^{\circ}\right)$ direction, and moreover, that the degree of natural calcification and the action of chemical decalcifying agents are of limited influence on the ultimate tensile strength of osteons.

After testing pieces of femoral and humeral cortex, Dempster and Liddicoat ('52) show that both the ultimate compressive strength and the modulus of elasticity (stiffness) in compression, as in wood, are greater along than across the grain. Dempster and Coleman ('61), using both bending and tensile tests, demonstrate that tibial bone, mandibular bone, and wood are all notably stronger in resisting deformations along rather than across the grain. Evans ('64) shows the mean tensile strength of embalmed wet cortical bone from tibiae is significantly greater than that from femora. Many tests along the grain show that cortical bone is much weaker in tension than in compression, the ratio of ultimate strengths being roughly three to five.

The foregoing findings imply that a cortical surface with a dominant grain pattern, which might be revealed by splitlines or other techniques (decalcified microscopic sections, ground sections, vascular canal injection, or microradiography), withstands indenting pressures and impacts better lengthwise than crosswise. Grain direction thus becomes a factor - hitherto unrecognized - that influences the initial response of the skull, or other bone, when it fractures.

\section{Skull architectonics}

The problem of skull strength in relation to environmental forces depends on several different, though related, considerations: (1) the physical characteristics of bone (including stiffness, yield strength, and ultimate strength in tension, compression, and shear); (2) the force systems that can act on the skull, including magnitude and manner of application; and (3) the architectural features of the skull, including the quantity of bone in different regions, the form of the different parts (with concern for discontinuities), and the direction of grain in each structure. The type of response - for example, safe transmission of forces, puncturing, chipping, shearing, and so on - is entirely dependent on these three considerations.

A number of the general physical properties of bones as a material have been summarized (Evans, '57). Probably most important is the fact that the ultimate compressive strength of human bone is about 25,000 PSI (pounds per square inch) in relation to an ultimate tensile strength of about 15,000 PSI; thus, bone is more likely to be damaged by tensile failure than by compressive failure (Dempster and Liddicoat, '52). Secondly, the tensile strength across the grain is much less the strength along the grain (Dempster and Coleman, '61).

The other two factors affecting strength - force systems and architectural considerations - must be discussed more fully if the overall problem of skull strength is to be understood.

Force systems on the skull. The head and skull are subject to at least three types 
of force systems. First, the skull acts as a container for the brain and other cranial contents, for the eye and orbital contents, for the components of the inner and middle ear, and for the tongue mass. In a static gravitational system, these parts, like a fluid, exert forces against certain containing bony walls. Under the influence of rapid acceleration of centrifugal force acting on the head, or of impacts between the head and other objects, the directions of these container forces will change, and the magnitudes of the forces may exceed the usual gravitational level for short periods. Such container forces are chiefly from the inside out, to be resisted by the containing bony surface.

A second set of forces on the skull is the intrinsic system of tensile and compressive forces associated with muscles, joints, and teeth. Muscle tensions are exerted on the exterior of the skull by the neck muscles to the occipital and temporal bones and by the occlusal group of the masticatory muscles. Other muscles (e.g., buccinator, superior pharyngeal constrictor) exert lesser forces. Equal and opposite compressive forces arise in reaction to the muscle tensions; for example, the action of the atlas bone on the occipital condyles and the forces on the teeth and on the temporomandibular joint.

Other forces, of an extrinsic nature, can impinge on the exterior of the skull. Examples of static loads on the skull and head such as bindings are rather special. Impacts, however, are common. They may be caused, of course, by falls, blows of all sorts, collisions as with the dashboard of a decelerating automobile), bullets and projectiles, and so on. When the head and body form a battering ram, as in football, in bodies ejected to the ground from an automobile, or in diving accidents, the crown of the head makes the impact but the vertebral column may also carry the body inertia into the skull base.

The effect of any force on bone will be to bend the bone, to stretch it, compact it, cause it to shear, or some combination of these types of deformation. The great variety of skull fractures reported in clinical literature suggests that every skull bone can fail if subjected to a force sys- tem of the proper kind and sufficient magnitude.

A fracture in response to applied forces must start at a particular millisecond of time at some localized area on the surface of the cortical layer of bone and spread from this point to produce a chip, large cleavage, crushed area, or comminuted fracture. In order to evaluate the cortical forms that were classified earlier, it will be necessary to examine some simple models of force systems on beams, plates, and shells.

Mechanics of cortical bone. Figure 12A introduces the basic mechanics of a deforming force (upper arrow) acting on a horizontal beam supported at each end. The total downward force (including the weight of the beam) will be equaled by the sum of the two resisting forces. Part of the middle downward force in relation to the right end force tends to rotate the right half of the beam in a counterclockwise direction; similarly, the middle downward and left end forces tend to rotate the left half in a clockwise direction. Each of these force arrangements is called a force couple and the measure of its tendency to bend is its moment or torque; in the figure, the moments are designated by the letter $M$ and the curved arrows. The amount the beam bends downward under the influence of the two force couples depends on its stiffness. These force couples shorten or compress the upper surface of the beam as indicated by the arrows $(\mathrm{c}=$ compression $)$ and stretches the lower surface $(t=$ tension $)$; but the middle plane of the beam (the neutral plane = N. Pl.) retains its normal length.

If the beam in figure $12 \mathrm{~A}$ were a bar of cortical bone under a deforming force system having a magnitude that exceeded the yield strength of the bone, a fracture due to excessive force would be a tension failure, since the ultimate tensile strength of bone is only about $60 \%$ of the ultimate compressive strength (Dempster and Coleman, '61; Evans, '57). Thus, a fracture would begin on the convex surface and spread toward the concave side as a deepening split.

Figures $12 \mathrm{~B}$ and 12C show broad plates of cortical bone instead of a narrow beam, resting on two supports near opposite 


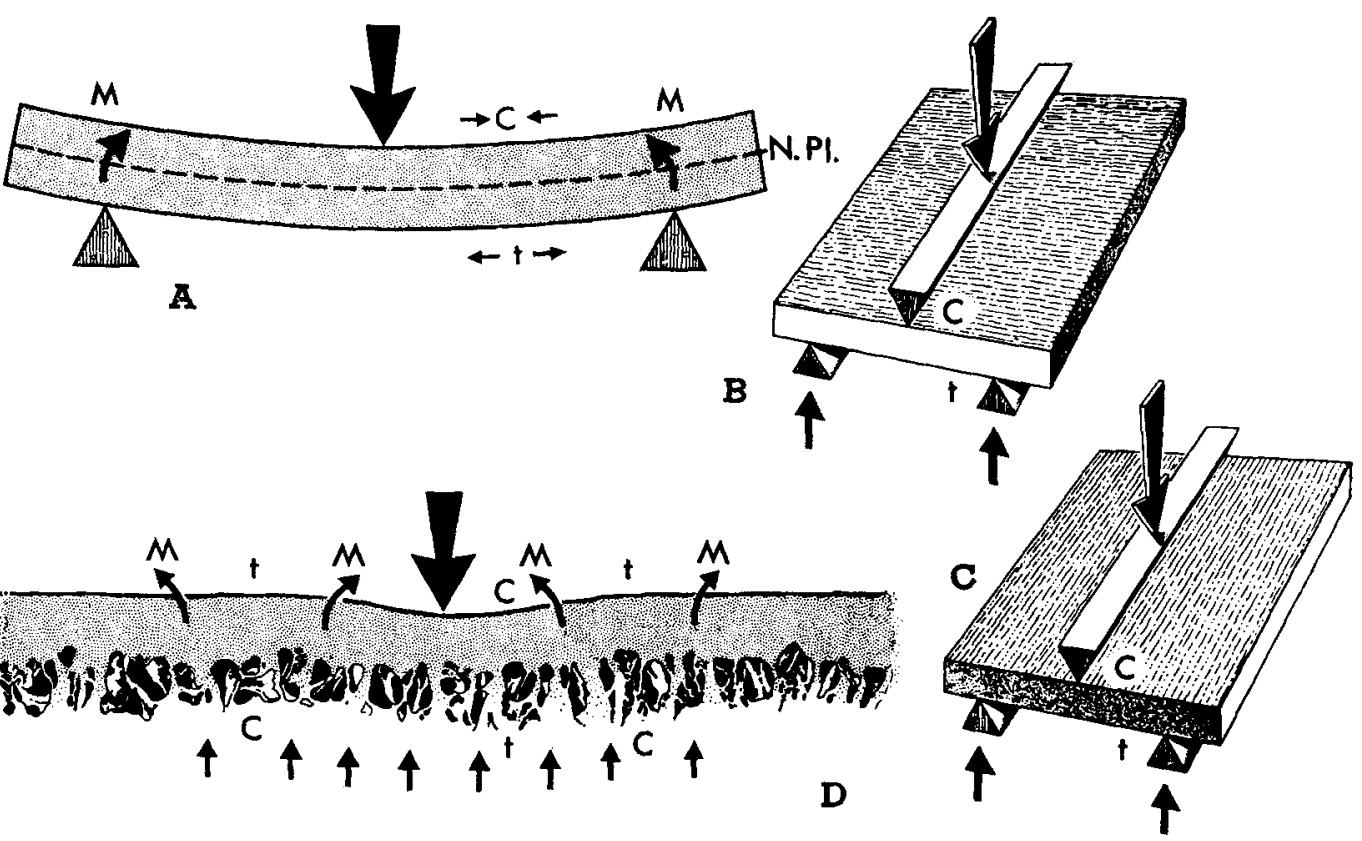

Fig. 12 Force patterns on thin plates with resultant deformations. A: A section through a plate resting on two supports with a deforming load at its middle. N.Pl., the neutral plane with shortened ( $\mathrm{c}$ - compressed) material on the concave side and elongated ( $t$ - tensed) material on the convex side. The curved arrows (M) imply bending moments. B: A plate with a lengthwise grain spanning the supports. C: A cortical plate of bone having grain oriented crosswise to the first is notably weaker to bending loads. D: A thin plate of indeterminate dimensions resting on an elastic substrate, as diploe. A concentrated deforming force, just short of a breaking force, is resisted over a wide area by the substrate. Inward bending moments about the deforming compressive force tend to cause a depressed deformation with a compressed (c) and tensed ( $t$ ) side. Compensatory outward bending moments with reversed compressed and tensed deformations appear at a distance.

edges; neglecting the weight of the plate in each case, the downward force (wedge and arrow) across the middle is exactly balanced by the sum of the opposite upward forces (arrows). The bending moments, the neutral plane, and the compressive (c) and tensile ( $t$ ) forces are similar to those of the beam (fig. 12A). In figure $12 \mathrm{~B}$, the length of the middle wedge is perpendicular to the grain of the bone; this force system causes bending along (parallel to) the grain. In figure $12 \mathrm{C}$, the wedge is parallel to the grain; this system causes bending across (perpendicular to) the grain. Practical experience with wood suggests that the plate in $12 \mathrm{~B}$ is less likely to split under a given force than that in $12 \mathrm{C}$, since resistance to bending along the grain (fig. 12B) is greater than resistance to bending across the grain (fig. 12C).
In fact, the experiments of Dempster and Coleman ('61) showed clearly that plates of tibial and mandibular bone (and birchwood) subjected to bending force systems are indeed much stronger in the lengthwise direction of the grain (as in fig. 12B) than in the crosswise direction (as in fig. 12C). In these studies, dry specimens of tibial cortex, mandibular cortex, and birchwood showed ultimate bending strengths crosswise to the grain (as in fig. 12C), that, in whole numbers, were only $17 \%, 43 \%$, and $8 \%$, respectively of the parallel-to-grain (fig. 12B) strength. The crosswise strength of watersoaked tibial pieces - more like fresh bone - was also $17 \%$ of the parallel-tograin strength shown by wet pieces.

Mechanics of cortical bone in the skull. The skull, of course, is not formed of simple machined plates of cortical bone. 
Most of the cranial and facial parts of the skull have inner and outer cortical bone and a middle layer of spongiosa or diploe. Air sinuses and pneumatic bone are also recognized specializations of the skull. Local areas of the bone in the temporal fossa, in the occipital base, and in the orbital and nasal walls have no spongiosa and consist of cortex alone. It will be convenient first to discuss cortical areas resembling plates or shells.

Many features of the mechanics of plates and shells, presented by Timoshenko and Woinowsky-Krieger ('59) relate to relatively thin, flat and curved engineering structures of sheet metal, concrete and other structural materials. One situation, in particular, applies to much of the inner and outer cortex of the skull: most of the cortex of the face and braincase may be viewed, in effect, as a continuous plate with indefinite limits (i.e., where edges may be ignored), supported by an elastic foundation. The plate may be viewed as having a large area relative to its thickness, and in this sense, it is like the paving of the runways of an airport or a public plaza. In such a system, localized forces cause localized deformations.

This concept (figure 12D) is illustrated by a layer of cortex supported by a foundation of spongiosa. A localized downward deforming force is balanced by equal and opposite forces of the spongiosa. The tendency is to depress the cortex locally (much as a person's foot depresses part of a rubber mat); bending moments (M) cause a downward bending about the downward force, with compressive stresses at the free surface and tensile stress on the spongiosa surface of the cortex. This deformation in turn produces, at a more outward position, compensating bending moments (M) in an opposite direction. The latter moments, in contrast to those near the applied force, produce a tension deformation of the cortex at the free surface and a compressive deformation at the spongiosa. In an isotropic material, a concave, circular depression results, and this is surrounded by a ring of radially tensed material. For a material like bone that is more susceptible to tensile than compressive failure, the initial fracture response would be tangential to the tensile forces. If the surface being considered has a parallel grain pattern, an elliptical deformation or failure should be produced. This woud be true for plane areas (P) of the skull with an oriented grain. A more broadly applied force should be transmitted through the spongiosa to the inner cortex, without localized deformation, and the whole thickness (all layers) of the bone should respond like a uniform plate.

Cranial fractures commonly cross sutures from bone to bone. The interlocking types of suture rarely separate. Doubtless, however, a suitable force applied directly over a simple (harmonic) suture should cause depression, separation, and possibly fracture. A consideration of the effect of force systems on the different types of sutures and synchondroses, however, leads away from the major concern of this paper with the texture and form of skull bone.

Architectural forms of the cortex. More specialized forms in the skull can be compared with common architectural and other structures for an evaluation of their characteristics. The Italian architect, Nervi ('56), and other architects of the past quarter century have pioneered with "form-resistant" structures; these include curved membranelike domes and roofs with a thickness that is small compared to the other dimensions. Unlike more usual framed structures, the strength of these structures, like that of boat hulls and aeroplane wings, is a consequence of the curvature of surfaces. Skull forms of cortical bone are closely related; they differ largely because of the underlying spongiosa. Figure 13 shows five forms that recur in parts of the skull other than the skull vault. At $\mathrm{A}, \mathrm{B}$, and $\mathrm{C}$, ridges are shown in representative cross sections of skull bones and in corresponding architectural models. Typically, ridges are caused by undulations of the whole cortical layer and are not mere localized thickenings of cortex. The characteristic grain direction is indicated in the models. Sketch A is a barrel arch; as an architectural form it might exist as a free standing structure, or it could be a viaduct below a roadway or the archway to a building. In such structures, both the weight of the masonry and any superimposed 
downward load act to maintain the form; thus, wedge-shaped pieces (called voussoir and keystone) are firmly pressed together by external pressures. In a bony ridge, the matrix grain is always lengthwise to the arch, so that whatever bony structure is responsible for the grain (lamellar bone, osteons, and so on) must be oriented in a predominantly lengthwise direction. Such elements, like the elements of the arch, would resist external forces efficiently. The elliptical dome or shell at $\mathrm{B}$ and the saddle-shaped ridge at $\mathrm{C}$ have similar cross sections and comparable fibrous patterns of the bony matrix; again, these patterns of grain represent mechanically advantageous arrangements for resisting external loads and pressures. The sections (mastoid process, frontal boss, and articular eminence) are all cut transversely to the direction of the ridges and the grain of the ridges; in each instance, the ridge is relatively thick bone an external pressure would tend to compact the material into a firm arch rather than cause it to collapse.

Troughs, (fig. 3T), such as the sulcus for the sigmoid and transverse sinus, the grooves for the internal carotid artery, and the arched part of the palatal arch, can be visualized as resisting pressure from within the curvature. Troughs are ordinarily much thinner-walled than bony ridges, and their structure is comparable to "membrane" structures in architecture (Nervi, '56; Timoshenko and WoinowskyKrieger, '59; Salvadori and Heller, '63). A cloth or membrane draped over two supports sags, but it will support weight in its concavity (fig. 13D). The sketches
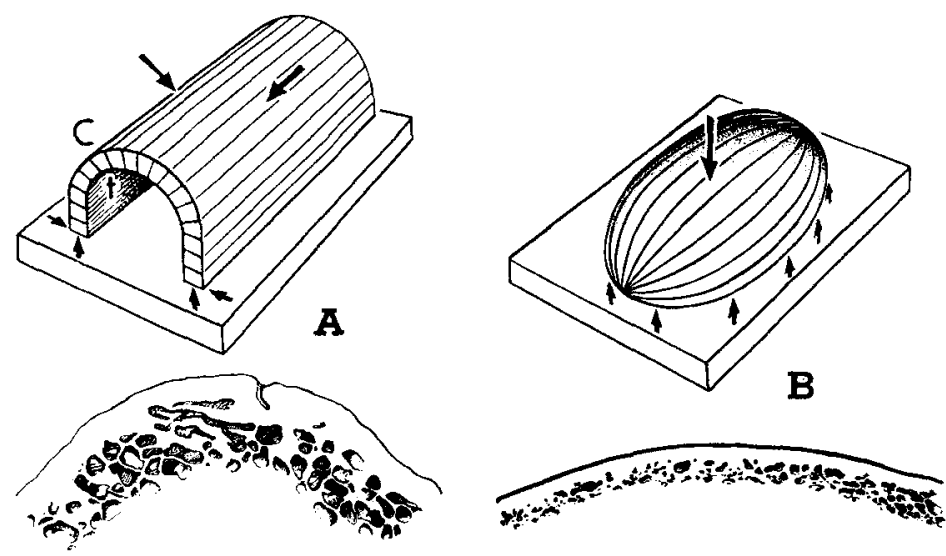

$\mathbf{B}$
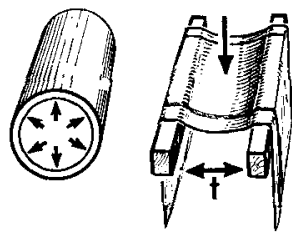

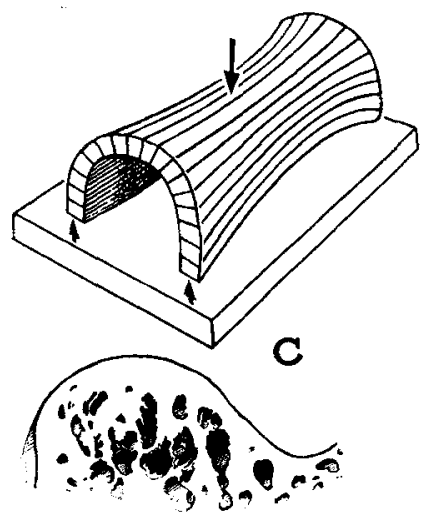

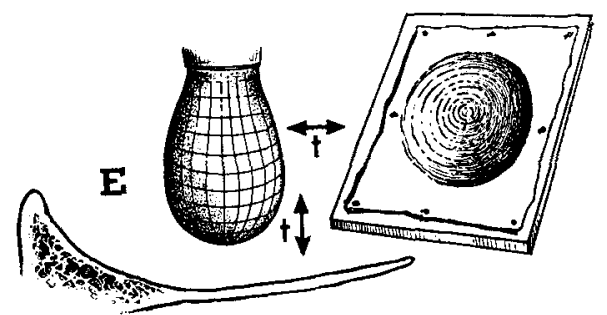

Fig. 13 Mechanical models illustrating certain structural characteristics. A: An arch made of elongate members resists downward external forces. $B$ and $C$ : The same is true for an elongate dome and a saddle-shaped arch. Below each model, the bone sections show (A) a transverse cut through mastoid process, (B) a vertical cut through the frontal boss, and (C) a sagittal cut through the articular eminence. D: Tubing subjected to internal pressure, a membrane hanging across two supports, a section through the thin-walled sulcus for the transverse venous sinus - in all these instances, pressure against the concave side of the trough is resisted by transverse, curved tensile fibers. E: A rubber balloon containing fluid, a rubber membrane sagging over a hole, and a section through the thin-walled lacrimal fossa of the orbit; in each instance, pressures are resisted by tensile fibers. In bony concavities, the circular grain predominates. 
at $\mathrm{D}$ also show rubber tubing subjected to internal pressure; the rubber yields primarily by stretching its circumference. A transverse circular covering, lining, or cordage, will effectively limit this yielding of the rubber and provide greater resisting strength. This is the direction of the grain in bony troughs. Thus, by analogy, the transverse grain pattern found in bony troughs should be suited for the type of strength needed in a trough.

Biconcave depressions (fig. 3C) can also be considered as membranes. Sketch $\mathrm{E}$ (fig. 3 ) shows a rubber balloon containing fluid. The fluid exerts an outward pressure on the surface "membrane" which is under tension in the directions shown; that is, both vertically and transversely along the lines encircling the fluid. As the volume and circumference increase with more fluid, each circular tension line must stretch. Likewise, a thin rubber membrane tacked to a board with a circular hole in it will resist the pressure of fluid through both circular and radial tensions (like those at the lowest part of the drop of fluid). In fact, the circular resistance will be greater than that across the surface, since for every unit that a diameter is increased, the circumference of the corresponding circle on the membrane must increase by $\pi$ times the diameter. Grain in the floor of bony concavities is generally circular and will thus resist such circumferential stretching, effectively tending to prevent outward deformation of the concavities.

As indicated in the classification, thin, unsupported edges and spines (figs. 3E and S) consistently have an elongate grain pattern that either parallels the edge or runs lengthwise in the spine to converge at the apex. This grain pattern, like the grain of an elongate wooden beam, since it lies in the direction of greatest strength, contributes to the resistance to bending. This is equally true for a cantilever beam, like a spine, and also for an unsupported edge.

Discontinuities as weak regions. Discontinuities require special consideration in the evaluation of the strength of the skull. The force borne by a structure is ordinarily treated in terms of a mean stress - the force per unit area of a cross section. For engineering or mechanical structures that have uniform cross sections, the average stress to be borne by a particular structure whether tensile, compressive, or shear stress) serves quite suitably as a criterion for evaluating the strength and the margin of safety of the structure. Experience has shown, however, that even small discontinuities in the surface or in the homogeneity of a member will increase the stress in one or more regions, the increase being out of all proportion to the mean stress across the structure. Thus, the part will fail more readily than might be assumed from the average stress values alone.

In this regard, there are two fields of physical science, namely, photoelasticity (Frocht, '41; Heywood, '52; Coker and Filon, '57) and the theory of plates and shells (Timoshenko and Woinowsky-Krieger, '59), that have supplied much evidence that discontinuities such as holes, sharp angles, notches, fillets, sudden changes in thickness, and so on - regardless of the material involved - cause great concentrations of stress. Regions of high stress concentration are regions of weakness and potential failure. Conversely, it has been pointed out (Heywood, '52) that mechanically sound designs avoid discontinuities and the likelihood of dangerous levels of stress.

In bones, discontinuities such as foramina, notches, edges, and sharp angles all concentrate stress much beyond average values, and it is here that fractures may begin to form. Discontinuities of skull bones, such as the mental foramina of the mandible or the cribriform plate of the ethmoid bone, may thus account for the frequency of fractures traversing these structures. Any of the discontinuities in the list above is presumptively a "weak" feature of the skull. Some discontinuities in the skull occur in groups as such complex congeries of edges, spines, and foramina as to defy systematic analysis. The region on each side of the skull bounded by the pterygoid process, the occipital condyle, the mastoid process, and the articular eminence of the temporal bone is such a region.

Spines and edges, as noted, have an elongate grain structure; foramina with 
thin edges are bordered by a region of circular grain texture. In each instance, the part is strengthened by its texture, but it cannot be said whether or not the mechanical advanage due to texture fully compensates for the stress-concentrating effect of the discontinuity. A spine that has an effective texture may show a stress concentrating discontinuity at the angle between its stem and its base. No doubt a force system that is potentially large enough will damage the skull somewhere, and some region of discontinuity is a likely site for fracture initiation.

Massive regional fractures. In addition to the localized fractures discussed above, certain regions of the face or cranium may exhibit extensive fractures. For example, there are greater masses of bone at the level of the palate, at the level of the orbital floor, and at the brow level than in the regions between. As a response to impacts, the teeth and the entire alveolar arch may be sheared across below the palate, separating the region from the rest of the skull. There may be transnasal-maxillary sinus shearing fractures or transorbital fractures. These are massive responses to impacts across the face at different levels. The fractures, basically, are at right angles to the cortical grain of the bone.

\section{Architectural and mechanical aspects of the skull vault}

The architecture of the skull vault as a gross form may be evaluated profitably in different ways. As indicated previously, braincase cortex is characterized predominantly by a random arrangement of fibrous matrix. Except in responding to a sharp localized force, like a grazing bullet, the whole cranial wall tends to react as a unit. A localized compressive force to the outer surface (fig. 14A) may result in tensile deformation of the underlying inner table, or possibly comminuted fractures of the inner table; but little or no damage may occur to the outer table, because the compressive strength of the bone is much greater than the tensile strength.

A more extensive group of fractures involves the cranium as a whole, irrespective of surfaces. As noted above, the cranial part of the skull acts as an oval container for the cranial contents. It is bounded, except for part of the basal region, by braincase bone consisting of inner and outer tables of cortex separated by a layer of diploe. The inner and outer cortical plates, except in old age, are generally thicker than facial-bone cortex in parts other than the mandible.

Figure 14B shows a saw-cut cross section of the skull, representing an approximate two-dimensional model that applies, more or less, to most of the skull vault. Under a compressive force system (fig. 14C) the skull section flattens like a ring. The inner cranial surface opposite the applied compressive forces shows tensile deformations; at $90^{\circ}$ around the section from the applied force, the deformations are reversed with tension acting on the external table and compression on the internal. Gurdjian and Lissner ('45) have demonstrated this type of skull deformation in experimental impacts. Thus, tensile fractures arising, contracoup, at a distance from an impact site on the skull vault may spread widely. Because they often extend widely from the site of fracture initiation, the fractures may reach into the foramina at the base of the skull or to the middle meningeal artery at the thin bone of the temporal fossa, resulting in hemorrhage or serious soft-tissue damage to cranial nerves. This tendency is increased by the stress-concentrating, boneweakening effect of discontinuities at the base of the skull.

The cranium should also be viewed as a three-dimensional structure; a barrel provides a satisfactory model (fig. 14D). A barrel may carry a load on its top, forming with the floor a compressive force system. The staves transmit compression while tending to bend outward; the hoops, however, are subjected to tensile forces which oppose the deformation of the staves. Similarly, an uncooked hen's egg may withstand a compressive force of 75 pounds if its ends are suitably padded (fig. 14E). Again, as compressive forces are transmitted from end to end, the sides tend to bulge like the hoop at $\mathrm{C}$, and internal stresses transverse to the length of the egg exerting tension to counteract the bowing outward. The egg, like the barrel, 

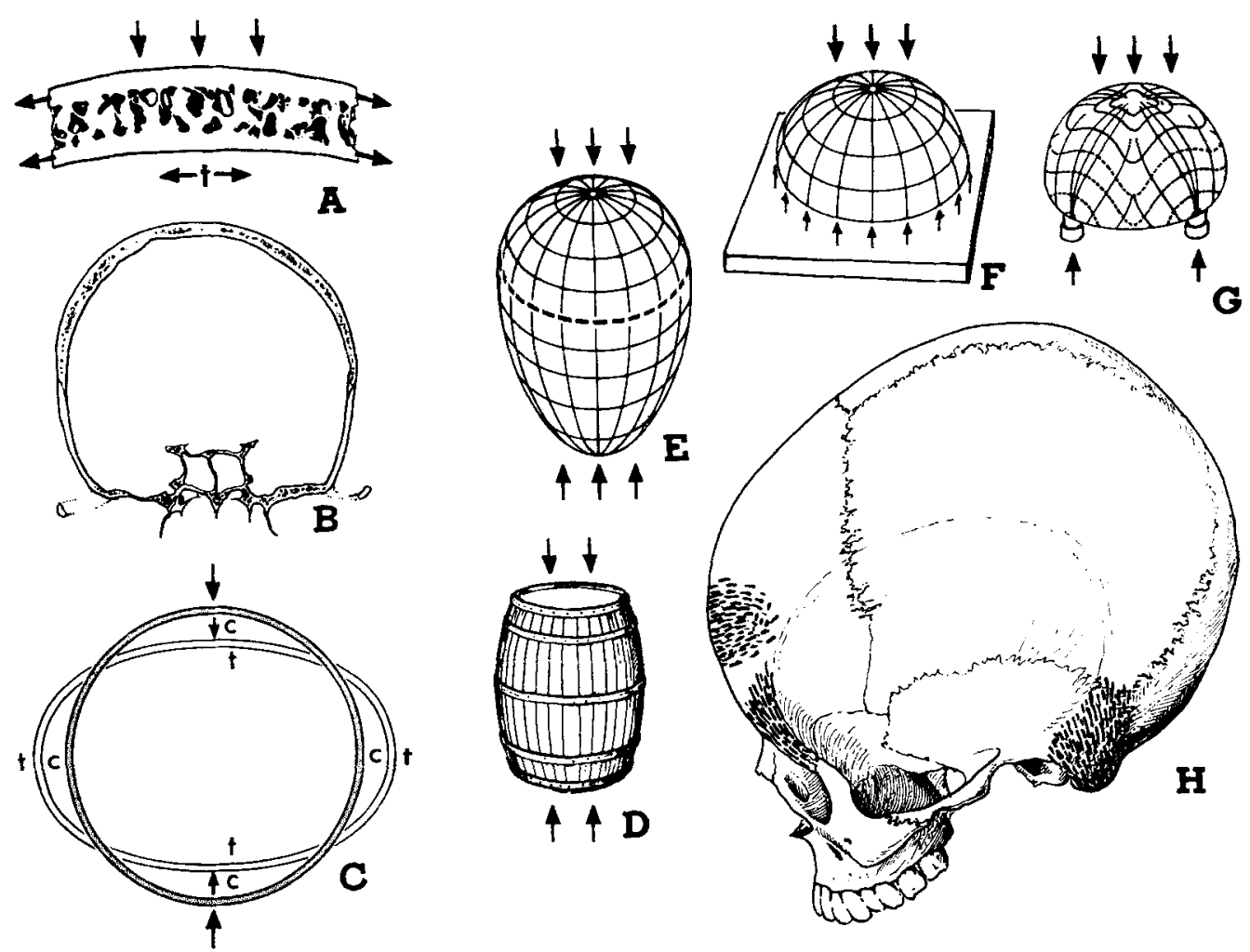

Fig. 14 A: Bone of the skull vault in section; exterior compressive force induces tensile deformation on inner table. $B$ and $C$ : Transverse section of skull under compressive force deforms like circular ring with four regions of high tensile $(t)$ and compressive (c) strains. D and E: In a threedimensional sense, the skull deforms like the barrel at $D$ and the egg at $E$. Vertical compression is transmitted from end to end and there are transverse circumferential tensions (suggested by the hoops in the barrel) and a three-dimensional force system analogous to that shown in the section at C. F: A dome on a horizontal support acts like the half of an egg above its equator. G: For a dome on pillars, the stresses focus toward the supports. $H$ : In the case of the cranial vault, the braincase with its random-patterned texture continues the grain pattern shown, both in the base and in several external (and internal) pillars. (Sketches $\mathrm{F}$ and $\mathrm{G}$ from Salvadori and Heller, '63, with permission.)

exerts both tensile and compressive forces (along lines such as those shown) to resist the external load; yet the egg shell has no grain structure.

Figure $14 \mathrm{~F}$ is an architectural dome corresponding to the broad end of the egg. Its mode of resisting a vertical force (its own weight, or an external force) is the same as that of the egg. If a dome is supported on pillars (fig. 14G), however, its weight must be counterbalanced at the support points where stress will be concentrated at higher levels.

In the skull the cranial vault is partly supported by ridges of bone with definite grain forming pillars or buttresses (as in fig. 14G), and is partly continuous with the base of the skull as in fig. 14F). The cortical tables of most of the skull vault have a random pattern of grain, forming a rough equivalent to the grainless structure of the egg. The buttresses (fig. 14H) are: on the external table of the skull vault - the two mastoid processes laterally with a vertical ridge grain; the two zygomatico-frontal buttresses laterally with a vertical fan of plane grain pattern; anteriorally, the frontal boss with a transverse ridge grain. Not shown on the inner table are vertical ridges or crests, with elongate grain, flanking the frontal and occipital parts of the superior sagittal 
sinus. An eccentric force on the skull vault would result in one pillar or another transmitting much of the load to the base of the skull and vertebral column. The stress distribution through the skull could be much more complex than that of a comparable force system on an egg.

\section{DISCUSSION}

Seven grain-form relationships are recognized in the adult skull: (1) a random pattern of braincase cortex, (2) planes and (3) ridges with elongate grain, (4) troughs with transverse grain, (5) concavities with circular patterns, (6) edges, and (7) spines. Concavities may show a superimposed trough or ridge structure, and troughs may be marked by localized ridges and planes. That is, trough patterns are dominant over concavity patterns, and ridge patterns are dominant over both trough and concavity patterns. Finally, there are a few small cranial areas that are random distributions in some skulls and planes in others; the skull vault proper, however, except for the forehead region and internal sagittal markings, has a random pattern throughout.

Bone resists deformation and fracture best in the long direction of its grain texture but is a relatively weak material crosswise. The classification of form-texture relationships presented in this paper includes most of the parts of the adult skull. They are discussed as architectural features of the skull, and their adequacy and limitations are analyzed in terms of their reaction to force systems and their proneness to fracture. All seven form-texture relationships over localized areas show grain directions that are in accord with the best mechanical use of the material of which they are made. Moreover, as shown in figure 5 , the various ridges appear to be deployed over the upper- and mid-face and over the skull base, both exterior and interior, so as to provide ribbing and buttressing that should add strength. Plane areas (fig. 4), strong in the direction of the grain and weak crosswise, are typically bounded by ridges, edges, or random braincase bone; the grain direction may be assumed to contribute more to strength than if it were oriented at $90^{\circ}$ to the grain actually seen in the skull. Most random patterned bone (fig. 4) gets its strength from the oval shape of the braincase, from the three layered structure, including diploe, of most of the skull vault, and from the thickness of the cortical tables. The other forms contribute less to total skull strength. Edges (fig. 7) and spines (fig. 6) have a grain pattern that provides localized reinforcement. Troughs (fig. 6) and concavities (fig. 7) are usually localized areas of thin bone; the arrangement of the texture, however, best resists surface pressures.

An eighth relationship - discontinuity - is recognized; this contains regions of potentially high stress concentration and weakness in the skull, even though certain discontinuities such as edges, spines, and thin foramina may show an effective use of texture.

In the mechanics and engineering field known as "strength of materials" homogeneous bars of test materials are subjected to detailed analyses of strains under force systems of different types. For many force situations, as a beam in bending or a column in torsion, the stresses vary from point to point, and maps or diagrams showing the directions of the maximum and minimum, or principal, stresses have been made. Sets of compression and tension lines always cross at right angles; the curves show the direction of stresses only, and the magnitudes of the stresses along the lines vary. For more than a hundred years, these lines of principal stress in homogeneous material have been designated "trajectories."

This term trajectory has now been taken over by some students of bone, and its original and only coherent meaning has been seriously distorted. In particular, since Meyer's demonstration of the trabecular patterns of the spongiosa of the femur and other bones (1867), the trabeculae of the spongiosa have even been regarded as specializations, or as trajectories, for carrying tensile or compressive forces, ignoring completely the weakness of the spongiosa as a material. Koch ('17), however, showed that in the femur, the trabecular pattern parallels the lines of maximum stress as the bone bears loads and transmits forces and thus serves 
as the most effective distribution of spongiosa. But Koch did not even mention the term trajectory.

In the traditional armchair view of the mechanics of the skull, the masticatory apparatus with its mobile jaw, teeth, and muscles, has been emphasized more than any other system for transmitting stresses. Pressure-carrying specializations in the form of pillars, beam, and buttresses have been postulated from the teeth to the upper skull; these extend vertically between the nose and orbit, through the zygoma, both through the zygomatic arch and the lateral orbital margin, and from the last molar region through the pterygoid process to the skull base. Muscular tensions bridge between the jaw angle and the zygomatic arch, and from the coronoid process to the temporal fossa with the bones transmitting forces to the teeth (Weinmann and Sicher, '47). The pillar idea is based on the general appearance of skull ridges and is not based on any bone measurements showing thick columns of increased cross-sectional area acting to reduce stress values (force per unit area).

When split-line patterns in the skull appeared to parallel the buttresses and pillars, the idea that these tracts served as cortical trajectories, or "cortical pressure lines," was formulated (Benninghoff, '25; Seipel, '48; Tappen, '53). No mechanically coherent interpretation involving force or stress was given to tell what these terms really meant. The implication, however, is that the tracts developed in the individual as response to functional stresses (Wolff's Law). This explanation must be speculative, since we know of no mechanism at the molecular level through which the processes of bone reorganization and growth might form pillars or pressure tracts under the influence of stresses transmitted along the pillars. The so-called masticatory pillars could be genetically determined growth specializations; the orientation of grain along them might or might not be a secondary mechanical adaptation.

The skull of an infant grows and changes its shape and form through childhood and adolescence, eventually acquiring adult architectural characteristics.
That is, the bone is resorbed, redeposited, and reconstructed until the multitude of eminences, processes, and fossae attain the structural forms and textures exhibited by an adult skull. Most of the texture of infantile bone is suppressed by secondary growth changes. This study points out that the grain of bone (as represented by the fibromatrix of the decalcified bone) and the form of bone in adult skulls are closely correlated. The work, however, suggests no clues as to how or why these relations came to be.

An alternate interpretation to the pressure line or trajectory idea of skull texture can be suggested. Since bone is especially weak crosswise to the grain for tension, compression, bending, and torsion, one may assume that crosswise properties, when not specifically arranged to best advantage (because of growth changes and new functional demands), present a weak feature to be modified by osteoblast and osteoclast activity as the bone grows under the stresses of normal functioning. Textures, thus, should reorient from infantile patterns as a response to bone growth influenced by the increasing size of the brain, orbital contents, and tongue, the formation of more cortex, more spongiosa, and more marrow space, the development of diploe, the formation of air sinuses, the adaptation to growing tooth germs, the superimposition of sexual specialization, and so on.

It is reasonable to propose that weak and inefficient bony tissues are replaced during bone reconstruction under the influence of intermittent stresses by bone textures of more effective orientation. Enlow and Bang ('65) have shown that gross form changes and growth of the maxilla involve complex reconstructive changes, periosteal deposition on certain surfaces, periosteal resorption on others, with either endosteal deposition or endosteal resorption on still other surfaces. The adult form-texture relationship presented in this paper should arise in time, as a compensation for mechanically weaker features of a grain oriented initially by embryonic and fetal growth. Such a view further proposes that a randomly oriented braincase texture should be stronger in all directions under tensile and compressive loads than is bone 
in the cross grain direction. The skull vault, like the egg, gains strength through its form and through the use of a structural material that is equally strong in all directions. Strength tests on parietal bone by Evans and Lissner ('57) suggest an intermediate level of tensile strength; the test, however, related to whole thickness bone and not to single tables of cortical bone.

\section{Editor's note}

This manuscript was edited from the final rough draft which Dr. W. T. Dempster had written shortly before he died.

\section{F. Gaynor Evans}

\section{LITERATURE CITED}

Ahrens, H. J. 1936 Die Entwicklung der Spaltlinienarchitektur des knochermen menschlichen Schadels. Morphol. Jahrb., 77: 357-371.

Ascenzi, A., and E. Bonucci 1964 The ultimate tensile strength of single osteons. Acta Anat., 58: 160-183.

Benninghoff, A. 1925 Spaltlinien am Knochen, eine Methode zur Ermittlung der Architektur platter Knochen. Verhandl. d. anat. Ges., 34th meeting, Vienna, 189-206.

1934 Die Architektur der Kiefer und ihrer Weichteilbedeckungen. Paradentium, 6: 2-20.

Bruhnke, J. 1929 Ein Beitrag zur Struktur der Knochencompakta bei Quadrupen. Morphol. Jahrb., 61: 555-588.

Bühler, E. 1934 Ưber die funktionelle Architektur der Kehlkopfknorpel des Menschen. Z. f. Morphol. u. Anthropol., 33: 227-260.

Coker, E. G., and L. N. G. Filon 1957 A Treatise on Photo-elasticity. 2nd. ed. revised by H. T. Jessop. University Press, Cambridge, England, xxxv + 720 pp.

Dempster, W. T., and R. F. Coleman 1961 Tensile strength of bone along and across the bone. J. Appl. Physiol., 16: 355-360.

Dempster, W. T., and D. H. Enlow 1959 Patterns of vascular channels in the cortex of the human mandible. Anat. Rec., 135: 189-205.

Dempster, W. T., and R. T. Liddicoat 1952 Compact bone as a non-isotropic material. Am. J. Anat., 91: 331-362.

Dowgjallo, N. D. 1932 Die Struktur der Compacta des Unterkiefers bei normalen und reduziertem Alveolarfortsatz. Z. f. Anat, u. Entw.gesch., Berlin, 97: 55-67.

Enlow, D., and S. Bang 1965 Growth and remodeling of the human maxilla. Am. J. Orthodont., 51: 446-464.

Evans, F. G. 1957 Stress and Strain in Bones. Their Relation to Fractures and Osteogenesis. Charles C Thomas, Springfield, Ill., $x+245$ pp.
1964 Significant differences in the tensile strength of adult human compact bone. Proc. European Bone and Tooth Symp. (Oxford, 1963), 1 ; 319-331.

Evans, F. G., and H. R. Lissner 1957 Tensile and compressive strength of human parietal bone. J. Appl. Physiol., 10: 493-497.

Frocht, M. M. 1941 Photoelasticity. 2 vols. J. Wiley and Sons, New York.

Gurdjian, E. S., and H. R. Lissner 1945 Deformation of the skull in head injury: a study with the "stresscoat" technique. Surg., Gynec. and Obstet., 81: 679-687.

Henckel, K. O. 1931 Vergleichend-anatomische Untersuchungen über die Struktur der Knochencompakta nach der Spaltlinienmethode. Morphol. Jahrb., 66: 22-45.

Heywood, R. B. 1952 Designing by Photoelasticity. Chapman and Hall, London, $371 \mathrm{pp}$.

Hultzkranz, W. 1898 tuber die Spaltrichtungen der Glenkknorpel. Verhandl. anat. Ges., Jena, 12: 248-256.

Ilberg, A. 1935 Ưber die funktionelle Architektur der Nasenknorpel und ihrer knöchernen Umgebung beim Menschen. Z. f. Laryngol., Rhinol, u. Otol., 26: 239-257.

Koch, J. C. 1917 The laws of bone architecture. Am. J. Anat., 21: 177-298.

Langer, K. 1861 Zur Anatomie und Physiologie der Haut. I. Utber die Spaltbarkeit der Cutis. Sitzungsber. d. Kaiserl. Akad. d. Wis., Wien. Mathematisch.-naturw. Classe, 44: 19-46.

Meyer, G. H. 1867 Die Architectur der Spongiosa. Arch. f. Anat., Physiol., u. Wiss. Med., 47: 615-628.

Nervi, P. L. 1956 Structures. F. W. Dodge, New York, $x+118$ pp.

Olivo, O. M., G. Maj and E. Toajari 1937 Sul significato della minuta struttura del tessuto osseo compatto. Bull. delle Sci. Med., 109: 369394.

Salvadori, M., and R. Heller 1963 Structure in Architecture. Prentice-Hall, Inc., Englewood Cliffs, N. J., $370 \mathrm{pp}$.

Seipel, C. M. 1948 Trajectories of the jaws. Acta Odontol. Scand., 8: 81-191.

Tappen, N. C. 1964 An examination of alternative explanations of split-line orientation in compact bone. Am. J. Phys. Anthrop., 22: 423442.

- 1954 A comparative functional analysis of primate skulls by the split-line technique. Human Biol., 26: 220-238.

- 1953 A functional analysis of the facial skeleton with split-line technique. Am. J. Phys. Anthrop., 11: 503-532.

Taxman, R. M. 1963 Incidence and size of the juxtamastoid eminence in modern crania. Am. J. Phys. Anthrop., 21: 153-157.

Timoshenko, S., and S. Woinowsky-Krieger 1959 Theory of Plates and Shells, 2nd ed. McGrawHill, New York, 580 pp.

Weinmann, J. P., and H. Sicher 1947 Bone and Bones, Fundamentals of Bone Biology. C. V. Mosby, St. Louis, $464 \mathrm{pp}$. 